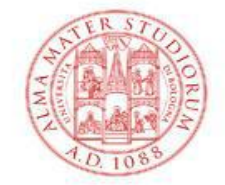

ALMA MATER STUDIORUM

PARTICIPACIÓN Y LIDERAZGO

DE MUJERES RURALES.

La Comarca del Guadalteba 1995-2011

Motivaciones y sentires

Presentado Por:

$M^{a}$ José Torres Escribano

Dirigido Por:

Cándida Martínez López.

Instituto de Estudios de la Mujer,

Universidad de Granada

Tutor De Apoyo:

Gustavo Gozzi.

Departamento de Sociología,

Universidad de Bolonia

Instituto Universitario de

Estudios de la Mujer.

Universidad de Granada.

Granada, septiembre de 2014
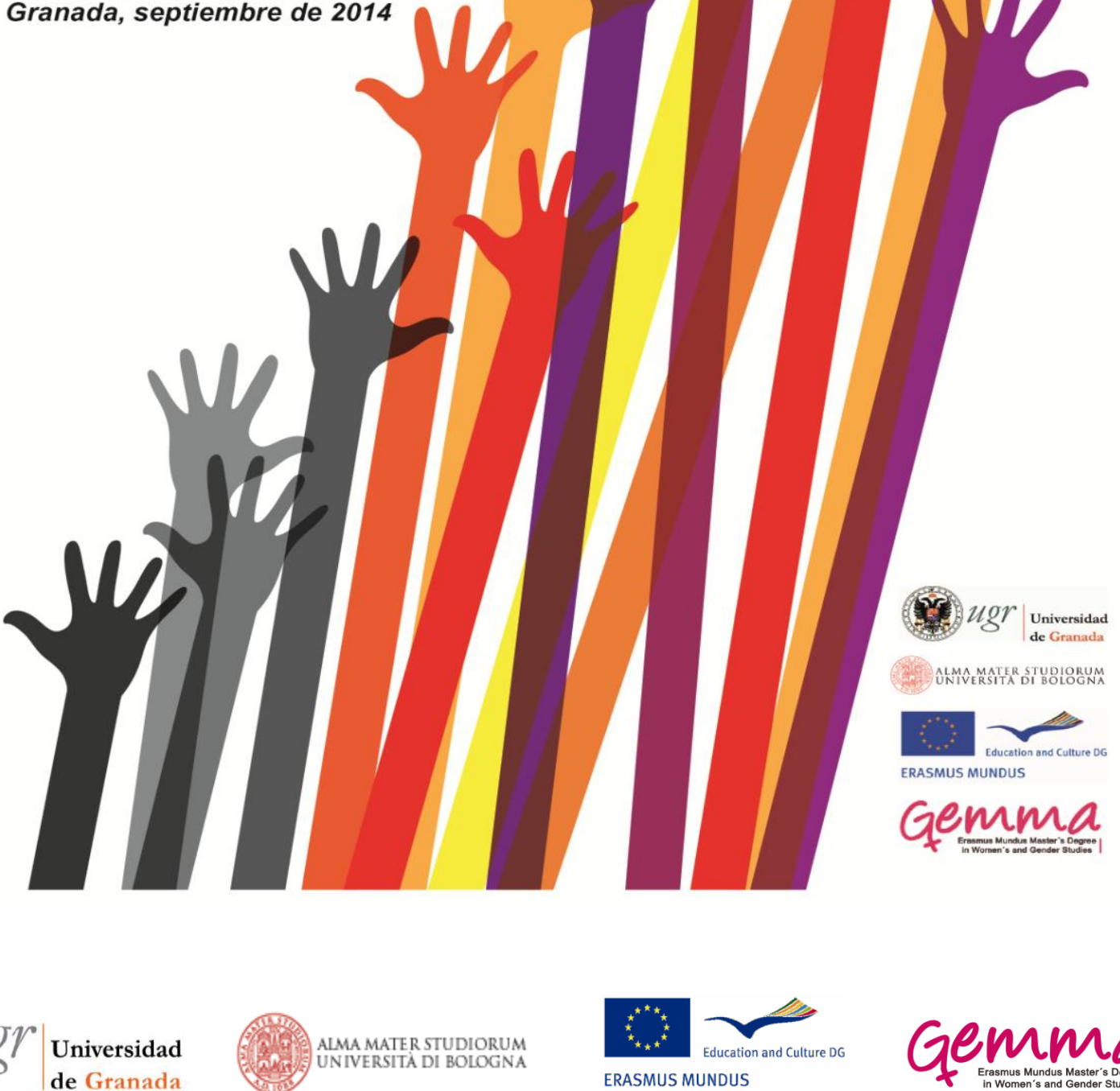

Gemma 


\title{
Participación y Liderazgo de Mujeres Rurales. La Comarca del Guadalteba 1995-2011
}

\author{
Motivaciones y sentires
}

Presentado por: $\mathrm{M}^{\mathrm{a}}$ José Torres Escribano

Dirigido por: Cándida Martínez López. Instituto de Estudios de la Mujer Universidad de Granada

Tutor de apoyo: Gustavo Gozzi. Departamento de Sociología Universidad de Bolonia

Fdo.: Cándida Martínez López. Instituto Universitario de Estudios de la Mujer. Universidad de Granada 


\section{Resumen}

El presente trabajo de investigación pretende ser una reflexión sobre la participación y el liderazgo de las mujeres de la zona rural malagueña de la comarca del Guadalteba. Analizaré las motivaciones que les llevan a participar en la política municipal y en el tejido asociativo de sus pueblos, la manera en que lo hacen, cómo contribuyen al desarrollo propio y al de su entorno, la percepción que tienen sobre el ejercicio de su liderazgo y si conciben su protagonismo como importante.

Palabras clave: mujeres, ruralidad, igualdad de género, política, participación, liderazgo, asociacionismo, motivación, visibilización.

\section{Riassunto:}

Il presente lavoro pretende essere una riflessione sulla partecipazione e la leadership delle donne della zona rurale del territorio di Guadalteba (Malaga). Analizzern le motivazioni che le portano a partecipare alla politica comunale e al tessuto associativo dei loro paesi, il modo in cui lo fanno, come contribuiscono allo sviluppo proprio e dei loro dintorni e del loro ambiente, la percezione che hanno sull'esercizio della loro leadership e se ritengono importante il loro protagonismo.

Parole chiavi: donne, ruralitą, paritą di genere, politica, partecipazione, leadership, associazionismo, motivazione, visibilizzazione. 
'Resolved lo que queráis, pero afrontando la responsabilidad de dar entrada a esa mitad de género humano en política, para que la política sea cosa de $\operatorname{dos}(\ldots)$ '

Clara Campoamor 


\section{Agradecimientos}

A las muchas y queridas personas que me han apoyado en este proceso a la vez duro e ilusionante, a mis compañeras y compañero de Máster por su apoyo y cariño, especialmente a Antonio, Liher, María, Paula y Viqui, nunca olvidaré todo lo que me habéis aportado a todos los niveles. A mi cotutor en Bolonia Gustavo Gozzi por valorar mi capacidad crítica en un momento en el que lo necesitaba. Y por supuesto a mi tutora Cándida Martínez López, por 'hacerme ver', por trasmitirme fuerza y abrirme un mundo nuevo y apasionante.

A Fran, mi 'personal trainer'... 


\section{ÍNDICE}

\section{I.- INTRODUCCIÓN: OBJETO DE ESTUDIO}

\section{II.- MARCO TEÓRICO, ESTADO DE LA CUESTIÓN, HIPÓTESIS Y}

METODOLOGÍA

Capítulo 1.- Estudios sobre las mujeres rurales. Enfoques desde la Ruralidad y el género.

1.1.- Cómo se integra la ruralidad y el género en las políticas de desarrollo y en la comunidad científica

Capítulo 2.- La Participación y el Liderazgo en las mujeres rurales.

2.1.- Impacto de las políticas feministas en la adquisición de derechos para las mujeres en el ámbito local

2.2.- El papel del Asociacionismo en el mundo rural.

2.3.- Liderazgo y ostentación del poder de las mujeres en Andalucía.

Capítulo 3.- El criterio de Interseccionalidad

Capítulo 4.- Hipótesis y Metodología

III.- LA COMARCA DEL GUADALTEBA

Capítulo 1.- Población, Nivel de estudios y Mercado de Trabajo

Capítulo 2.- Evolución de la Comarca y Antecedentes desde el punto de vista de la igualdad de género

IV- PARTICIPACIÓN Y LIDERAZGO DE LAS MUJERES EN LA COMARCA DEL GUADALTEBA: UN COMPLEJO PROCESO DE CAMBIO Y RESISTENCIA

Capítulo 1.- Mujeres en las asociaciones. La participación pública en la comarca del Guadalteba. 
Capítulo 2.- Mujeres, participación política y liderazgo en la comarca del Guadalteba.

2.1.- Representación de las mujeres en las listas electorales

2.2.- Género y Empoderamiento de las Mujeres en la vida política

2.2.1.- Motivaciones y razones para acceder a la vida política municipal

2.2.2.- Cómo viven las mujeres el Liderazgo en la política municipal

2.2.3.- Consideraciones sobre el Feminismo y la Igualdad

Capítulo 3.- La Acción Institucional: El Consejo Comarcal de la Mujer del Guadalteba

Capítulo 4. - Motivaciones, percepciones y sentires

V.- CONCLUSIONES

VI.- REFERENCIAS BIBLIOGRÁFICAS

VII.- ANEXOS 


\section{I. - INTRODUCCIÓN: OBJETO DE ESTUDIO}

La presente investigación está centrada en el análisis de la participación y el liderazgo de las mujeres de la comarca del Guadalteba desde 1995 a 2011. Dicha comarca se ubica en una zona rural de la provincia de Málaga.

En ella se estudia el proceso de incorporación de las mujeres a la vida pública, el grado de asunción de responsabilidades, su liderazgo social y político y también desde un punto de vista emocional, las motivaciones que las llevan a participar y tener liderazgo, si lo asumen, por qué lo hacen, si son conscientes de que lo tienen y a través de qué mecanismos lo ponen en práctica. Este objeto de estudio nace de mi experiencia como técnica de inserción socio laboral para mujeres en un programa del Instituto Andaluz de la Mujer durante varios años en esta comarca ${ }^{1}$. A raíz de aquí me surge la curiosidad por averiguar la voluntad de participación, de toma de conciencia del liderazgo y la percepción que tienen las mujeres rurales como seres protagonistas de sus vidas y de su entorno.

Para ello analizaré la participación política a nivel de listas electorales y representación política en los ayuntamientos y su protagonismo en otro tipo de instancias tales como las asociaciones y otros organismos de organización política existente; esto es, la participación pública en las asociaciones de mujeres. Los ámbitos de participación que consideraré son:

- Mujeres como agentes directas de la política local: alcaldesas, concejalas y representantes de las listas electorales.

- Mujeres como actoras y agentes directas a través de la participación en las asociaciones de mujeres.

El periodo que escojo va desde la fecha de creación en 1996 del Consejo Comarcal de la Mujer $^{2}$ (CCM) hasta las últimas elecciones municipales.

\footnotetext{
${ }^{1}$ Primero Programa OPEM: Orientación y Preformación para Mujeres y luego Programa UNEM: Unidades de Empleo de Mujeres. Estos programas parten de la iniciativa comunitaria NOW (Nuevas Oportunidades para la Mujer) y son programas específicos para la promoción de las mujeres en el ámbito rural de las políticas de desarrollo europeas.

${ }^{2}$ En adelante CCM
} 
El intento de consensuar lo que determina lo rural y lo que no ha hecho correr ríos de tinta en cuanto a mostrar lo que caracteriza a dichas zonas desde varios puntos de vista, sobre todo a lo que a datos demográficos se refiere. Si bien es cierto que desde el feminismo y otras instancias se ha abordado con mucho interés el papel de las mujeres rurales y sus particularidades, existen pocos estudios que analicen su papel en las estructuras políticas locales. Es por ello que con la presente investigación quiero reflejar una realidad no estudiada hasta ahora. Mi intención es contribuir a visibilizar y dar protagonismo a las mujeres de la Comarca del Guadalteba y al papel que tienen en su participación sociopolítica desde el compromiso y la gran admiración que siento hacia ellas y desde mi propia identidad de mujer rural, e intentar aportar conocimiento que pueda servir para estudios posteriores y como herramienta de transformación. He aquí mi forma de rendir homenaje a las mujeres rurales en general y a las que participan en el desarrollo de sus pueblos en particular. 


\section{II.- MARCO TEÓRICO Y ESTADO DE LA CUESTIÓN}

En el estado de la cuestión tendré en cuenta dos ejes fundamentales para explicar la trayectoria de los estudios que han llevado al conocimiento de la realidad rural y de las mujeres en la ruralidad. Por un lado los informes oficiales de organismos españoles, europeos e internacionales, por otro los análisis desde la teoría feminista. Ambos han contribuido de forma especial a la creación de conocimiento, al desarrollo de las investigaciones y a la puesta en marcha de políticas específicas de igualdad en las zonas rurales. Este será el camino que recorreré para intentar ofrecer una panorámica que nos permita entender la progresión hacia el interés de las zonas rurales y del potencial de las mujeres en ellas.

\section{Capítulo 1.- Estudios sobre las mujeres rurales. Enfoques desde la Ruralidad y el género}

Cuando definimos lo rural normalmente lo hacemos en contraposición a lo urbano; esta ha sido la imagen tradicional que se ha dado (Newby Howard y Sevilla Guzmán Eduardo, 1983) ${ }^{3}$ y aún nos basamos sobre todo en criterios de espacio geográfico y de insuficiencia de servicios disponibles, sobre todo, para delimitarlo. Pero ninguno de estos criterios recoge la pluralidad y la diversidad de los hábitats rurales ya que existen muchas diferencias entre comarcas y pueblos y características que las hacen únicas. El giro cultural en las ciencias sociales y la evolución de los espacios rurales hace necesario el análisis de la diferencia para entender la situación de las mujeres y sus relaciones con lo masculino (Little, 2001) ${ }^{4}$.

A continuación expongo el proceso que ha llevado a la nueva concepción de lo rural y a la implementación de la perspectiva de género en ella. Este caminar nos servirá para entender mejor la situación actual y ver la continua progresión de la incorporación

\footnotetext{
${ }^{3}$ NEWBY Howard y SEVILLA GUZMÁN Eduardo (1983). Introducción a la Sociología Rural. Madrid: Alianza Universidad.

4 En BAYLINA FERRÉ, Mieria y SALAMAÑA SERRA Isabel (2006). 'El Lugar del Género en Geografía Rural'. Boletín de la A.G.A. n 41-2006, págs. 99-112.
} 
de la categoría género en la ruralidad, tanto desde el punto de vista político como de estudio disciplinario.

\section{1.- Cómo se integra la ruralidad y el género en las políticas de desarrollo y en la comunidad científica}

No podemos hacer referencia a la ruralidad y a los estudios de género en la misma sin hacer referencia al desarrollo rural y a cómo las políticas rurales han ido evolucionando en los últimos 40 años. Partiendo del ejemplo de la provincia de Málaga, entre los años 60 y 70, donde apenas existía la mecanización agraria, se crean las Agencias de Extensión Agraria cuyos fines fundamentales son las explotaciones, los jóvenes ${ }^{5}$ y el desarrollo comunitario y que contribuyen a la propia modernización del espacio rural. Empieza a observarse un escenario cambiante pero en el que aún queda muy lejos la integración de las mujeres en las políticas públicas de desarrollo rural.

El ingreso de España en la Comunidad Económica Europea en el año 1986, va a suponer un giro completo en sus políticas agrarias. La pluralidad de las economías rurales y su diversificación, teniendo en cuenta la realidad local, pasa a ser un objetivo principal de estas políticas europeas. De acuerdo con este cambio, se dota de presupuesto a los programas y proyectos de desarrollo rural a través de los fondos estructurales europeos para apoyar a las zonas rurales y a los grupos más débiles en el espacio europeo. Surgen varias iniciativas en pro de la diversificación y el avance de los espacios rurales. La primera será el LEADER I ("Relaciones entre Actividades de Desarrollo de la Economía Rural") en 1991, le seguirá el LEADER II en 1994 en la que se involucran las administraciones autonómicas como organismos intermediarios y el PRODER (Programa Operativo de Desarrollo y Diversificación Económica de Zonas Rurales) en 1994 (Giardin y Galán Federico José, 2001) ${ }^{6}$. Continuarán varios marcos de desarrollo más, siendo el actual y vigente el marco de la Estrategia Europa $2020^{7}$ e iniciativas y programas específicos para la integración de la igualdad de oportunidades ${ }^{8}$ destacando la iniciativa NOW (Nuevas Oportunidades para la Mujer) y el LEADER II,

\footnotetext{
5 Jóvenes hombres del sector agrícola, las mujeres jóvenes no están contempladas aún.

${ }^{6}$ GIARDIN Y GALÁN, Federico José (2001). El desarrollo rural en la provincia de Málaga. Jábega. Núm. 87. Pp. Exima. Diputación Provincial de Málaga.

${ }^{7}$ Para más información consultar la web: http://ec.europa.eu/europe2020/index_es.htm

${ }^{8}$ La política europea tiene su origen en el Artículo 119 del Tratado de Roma. Este tratado estipula que el principio de remuneraciones sea igualitario para hombres y mujeres.
} 
PROGRESS 2007-2013 (Programa de apoyo financiero para la aplicación efectiva del principio de Igualdad entre mujeres y hombres y fomentar la integración de la Igualdad en las políticas de la Unión Europea), la Red Europea de Mujeres con responsabilidad política y económica de 2008, como los que has contribuido de manera especial a la participación de las mujeres en el desarrollo rural (Bayona Cristina, 1999). Mediante la puesta en práctica de estos programas de desarrollo se va integrando el interés por las mujeres y la inclusión de las mismas en ellos.

No debemos olvidar que esta apuesta por lo rural, ha ido en paralelo con los compromisos en materia de igualdad que la propia unión europea ha ido acordando. El Tratado de Amsterdam aprobado por los 15 países miembros de la Unión Europea en el año 1997 establece que la igualdad debe servir para luchar contra la discriminación por motivos de sexo, edad, origen racial y étnico, discapacidad, religión y orientación sexual. En este mismo año se crea el Instituto Europeo de la Igualdad de Género como organismo específico de la igualdad de género 9 . Les seguirán otros tratados como el de Niza o el de Lisboa, y estrategias políticas que redundarán en el compromiso hacia el avance de la igualdad de género en Europa. Actualmente está en vigencia la Estrategia para la Igualdad entre mujeres y hombres para el periodo $2010-2015^{10}$.

En el contexto internacional es importante destacar el trabajo de las Naciones Unidas (ONU) que desde el Comité para la Eliminación de la Discriminación contra la Mujer $(\mathrm{CEDAW})^{11}$ y las sucesivas Conferencias Internacionales de la Mujer, México (1975), Copenhague (1980), Nairobi (1985), Beijing (1995) y sus revisiones Beijing +5 y Beijing +10), han contribuido a crear un escenario global de reivindicación de los derechos de las mujeres. En el terreno que nos ocupa, destaca la Plataforma de Acción de Beijing que tiene entre sus objetivos la adopción de medidas para garantizar la igualdad en el acceso a la participación de las mujeres en las estructuras de poder ${ }^{12}$. Nos encontramos en el proceso en el que va cambiando la orientación en la manera de implementar estos programas; el cambio del enfoque Mujeres en el Desarrollo (MED)

\footnotetext{
${ }^{9}$ Actualmente la existencia del Instituto Europeo de la Igualdad de Género es más a nivel oficial porque su actividad es bastante baja.

10 Para más información visitar: http://ec.europa.eu/justice/gender-equality/index_es.htm20142020/index_es.htm

11 Unificados en ONU Mujeres a partir de su creación, véase la web para más información: http://www.unwomen.org

12 Véase la web de ONU Mujeres para ampliar información: http://www.unwomen.org/es/how-wework/intergovernmental-support/world-conferences-on-women
} 
de los años 70 al enfoque Género y Desarrollo (GD) en los 80. Este paso fue muy importante para considerar que la incorporación del género no puede abordarse solamente desde acciones concretas destinadas a las mujeres como hacia el enfoque MED, sino que se debe partir de una mirada más amplia en la que la perspectiva de género (no debemos olvidar que esto incluye también a los hombres) es un objetivo en sí y no un instrumento más en la planificación de programas y proyectos de desarrollo ${ }^{13}$.

En lo que específicamente a las mujeres rurales se refiere, en España existe un marco legislativo y de políticas públicas que vela por los intereses específicos de las mujeres rurales. Las más relevantes son la Ley Orgánica 3/2007 de 22 de marzo para la Igualdad efectiva de Mujeres y Hombres, el Plan de Igualdad entre Mujeres y Hombres 2007-2013, el Plan de Igualdad de Oportunidades entre Mujeres y Hombres en el Medio Rural 2007-2013, el Plan Estratégico de Igualdad de Oportunidades entre mujeres y hombres 2008-2011 del Ministerio de Trabajo y Asuntos Sociales y la Ley 35/2011 sobre titularidad compartida de las explotaciones agrarias. También existen redes creadas desde la propia administración como por ejemplo la 'Red de Mujeres rurales y urbanas de Andalucía ${ }^{14}$ de la Consejería de Presidencia e Igualdad de la Junta de Andalucía, así como el reconocimiento del Día Internacional de las Mujeres Rurales que se celebra el 14 de octubre para reivindicar ese día.

Todas estas iniciativas políticas, han dibujado un nuevo panorama de la igualdad de género en nuestro país, en Europa y en el mundo y, sobre todo han contribuido a la transformación de los territorios rurales y a la visibilización de las mujeres en ellos. Por supuesto les han seguido los compromisos estatales y autonómicos en materia de legislación y políticas de igualdad que han llevado a nuestro país a ser referente mundial (Forest Maxime y Platero Méndez Raquel, 2008). Desde la creación del Instituto de la Mujer en 1983, de la Secretaría General de las Políticas de Igualdad en 2004 hasta el Ministerio de Igualdad en $2008^{15}$, la igualdad de género y la lucha por los derechos de las mujeres en general, ha experimentado un impulso muy considerable. Por

\footnotetext{
${ }^{13}$ Véase CALATRAVA, Javier (1997). 'Importancia de la integración de la mujer en los procesos de desarrollo'. Ponencia presentada a las Jornadas 'La Mujer: Clave del Desarrollo Rural' celebradas en Campanillas (Málaga), Octubre 1997. Organizadas por la Consejería de Agricultura y Pesca-Junta de Andalucía. Consejería de Agricultura y Pesca.

${ }^{14}$ Para más información visitar: http://www.redmujeresruralesyurbanas.com/

${ }^{15}$ La creación de este ministerio supuso un referente a nivel mundial. Por desgracia desaparecido en el año 2010 e integrado en el Ministerio de sanidad, Política Social y e Igualdad.
} 
comunidades autónomas destaca Andalucía, siendo pionera en políticas de igualdad y en marco legislativo autonómico.

Este impulso también se ha hecho latente a través del diseño específico de planes de igualdad como instrumento político (Expósito Molina Carmen, 2012), además de las estrategias institucionales para hacer efectivas la igualdad de género a través de los planes, la aplicación de la transversalidad o mainstreaming de género ${ }^{16}$ y las acciones positivas tan importantes para las mujeres en las zonas rurales (Bustelo Ruesta María, 2008). Me detengo en señalar el enfoque del mainstreaming por suponer una estrategia política importantísima cuyo objetivo es la integración de las mujeres en el desarrollo. Comienza a ser exigido en la III Conferencia de las Mujeres de Naciones Unidas donde se reivindicó el papel de las mujeres en los países en vías de desarrollo y con ello de las mujeres rurales.

La integración del género como categoría de análisis y de la mirada feminista en los estudios rurales también ha supuesto un logro muy importante para ayudarnos a comprender la situación global de las mujeres que habitan estos espacios (Whatmore, 1989; Van der Burg y Endeweld, 1994). Encontramos investigaciones que ponen el énfasis en tratar lo rural desde un punto de vista valorativo en donde las diferencias que lo determinan en contraposición con lo urbano cada vez son menores. Lo rural ya no tiene que ver con el mundo cerrado y homogéneo y contrapuesto a lo urbano tal y como nos exponía la sociología tradicional (Newby Howard y Sevilla Guzmán Eduardo, $1983)^{17}$. Supone una categoría construida en la que esa dicotomía ya no tiene sentido y es más un proceso de interacción en la que la propia sociedad actual está construyendo su propia percepción a través de ese interactuar (Berger Peter y Luckman Thomas, 1998) ${ }^{18}$. Marc Mormont (1990) nos argumenta que ya no existe un único espacio rural, sino que existen tantos espacios sociales como territorios imaginados (haciendo referencia al enfoque de representación social) y que es debido a los cambios económicos y sociales. Desde este punto de vista, lo rural no es rural solamente por sus características estructurales, poblacionales, económicas, etc. sino que son las propias personas las que construyen ese imaginario, son ellas las que crean los espacios. Se abre

\footnotetext{
${ }^{17}$ En GARCÍA RAMÓN, Maria Dolors y BAYLINA FERRÉ, Mireia (2000). El nuevo papel de las mujeres en el desarrollo rural. Barcelona: Oikos-Tau.

${ }^{18}$ En DÍAZ MÉNDEZ, Celia. Aproximaciones al arraigo y desarraigo femenino en el medio rural: : mujeres jóvenes en busca de una nueva identidad rural. Papers 75:63-84.
} 
pues un camino hacia el interés por el análisis desde la 'otredad' y del cómo se construye la identidad en los espacios rurales (Cloke, 1997; Murdoch y Pratt, 1993). Y por supuesto surge el interés del estudio por el género en la ruralidad, desde estas disciplinas, y del papel preponderante de las mujeres y su nuevo protagonismo en el desarrollo. Además, estos cambios sociales que se vienen produciendo están conllevando un giro hacia lo rural; 'la superación de los límites de lo agrario en beneficio de lo rural, permite hablar de 'desagrarización' (San Pedro Gallego Rosario, 1996), factor que no debemos confundir con el abandono de la práctica agraria sino como riqueza del medio y del creciente interés por los estudios rurales (Figueroa Nieto Cristina, 2003) y más concretamente del género en la ruralidad como lo atestiguan estas investigaciones ${ }^{19}$. A pesar de todos estos factores cambiantes de los que se ha estado haciendo mención, hay que reseñar que las mujeres y los hombres rurales poseen aún unos roles muy marcados y creencias más arraigadas en la asunción de lo que deben ser y del cómo tienen que actuar dentro de la sociedad patriarcal rural. Es por ello que se hace tan necesario tener esto en cuenta en el análisis porque tienen matices diferenciales y consecuencias para las mujeres (Baylina Ferré Mireia, Salamaña Serra Isabel, 2006).

Según datos del Instituto Andaluz de la Mujer, en Andalucía el 54,92\% de la población reside en municipios rurales, siendo el 49,82\% de la población rural mujeres (2.244.394 de mujeres están presentes en el mundo rural andaluz, y 2.260.495 de varones). Un dato significativo es el indicador de titularidad en las explotaciones agrarias, que apenas ha sufrido cambios a pesar de la entrada en vigor de la Ley 35/2011 sobre titularidad compartida de las explotaciones agrarias. Las titulares de explotaciones agrícolas son $69.279(29,9 \%)$ y las jefas de explotaciones agrarias, el $21,9 \%{ }^{20}$.

Quiero destacar el estudio de 2010 de Lina Gálvez y Mauricio Matus López sobre bienestar y desarrollo de las mujeres en el ámbito rural andaluz ${ }^{21}$ en el que se presenta una panorámica muy interesante de las mujeres rurales desde el ámbito

\footnotetext{
${ }^{19}$ Por otro lado, existen nuevos planteamientos, sobre todo en Reino Unido sobre el llamado 'idilio rural' que no es más que dar por hecho de que los espacios rurales y el vivir y estar en el campo conllevan una vida saludable y de cohesión social ejemplar (Clocke, 2003). Esta visión está siendo empleada comercialmente para sacar provecho de esta posición fragmentada de la ruralidad.

${ }^{20}$ INSTITUTO ANDALUZ DE LA MUEJR (2010). Realidad de mujeres y hombres en Andalucía.
} 
económico y social ${ }^{22}$ y a Maria Dolors García Ramón y Mireia Baylina Ferré que desde la geografía rural han analizado el papel de las mujeres españolas en el desarrollo rural y han estudiado la importancia de su participación en él y el recorrido que ha experimentado. Es de enfatizar la revisión que han hecho estas dos autoras sobre las revistas internacionales (Sociología Ruralis y Journal of Rural Studies) y españolas como Agricultura y Sociedad y Revista de Estudios Agrosociales, sobre la progresión en el tratamiento y la presencia de las mujeres rurales en estas publicaciones. Ellas también han puesto de manifiesto la relevancia de algunos grupos de investigación en Geografía y Sociología sobre todo, por el interés de aplicar el género a sus disciplinas desde el planteamiento de lo rural. ${ }^{23} Y$ por supuesto destacar los informes y estudios que ha financiado el Instituto Andaluz de la Mujer junto a teóricas importantes para dejar constancia del conocimiento teórico y del avance de la temática que se está tratando ${ }^{24}$.

22 GÁlVEZ, Lina y MUÑOZ Mauricio (2010). Trabajo, Bienestar y Desarrollo de las Mujeres en el ámbito rural andaluz: estudio para el diseño de políticas de igualdad y desarrollo. Instituto Andaluz de la Mujer. Sevilla

23 Para ampliar información, véase GARCÍA RAMÓN, Maria Dolors y BAYLINA FERRÉ, Mireia (Eds.). 2000. El nuevo papel de las mujeres en el desarrollo rural. Barcelona: Oikos-Tau.

24 Consultar INSTITUTO ANDALUZ DE LA MUJER: Centro de documentación María Zambrano: http://www.juntadeandalucia.es/institutodelamujer/index.php/centrodedocumentacion 


\section{Capítulo 2.- La Participación y el Liderazgo en las mujeres rurales}

Los debates sobre la historia de la participación política en las mujeres en España, tienen una larga trayectoria en los estudios feministas ${ }^{25}$. No es este trabajo el lugar para ahondar en dicha reflexión, por ello me centraré en los informes realizados desde organismos oficiales y en los estudios académicos desde el análisis feminista de las mujeres rurales.

También existen muchos estudios sobre los estilos de liderazgo que caracterizan a mujeres y hombres pero sigue siendo un debate sobre el que profundizar. A nivel general me gustaría destacar el estudio de Jean Blondel (1987) que habla de dos estilos de liderazgo: el alcance que abarca en los espacios políticos donde se ejerce y la intensidad o efectos deseados al ejercerlo. Por lo tanto es muy interesante ver las repercusiones que estos dos parámetros tienen en el ejercicio político de las mujeres tanto en niveles abarcables como en resultados obtenidos. Los procesos de socialización y de educación diferencial conllevan que la capacidad de las mujeres para participar en política venga dada independientemente de sus capacidades; en palabras de Bussby, 'la meritocracia suele llevar una estampa claramente masculina'.

Las mujeres están expuestas a exámenes continuos simplemente por su condición de mujeres ${ }^{26}$. Las estructuras de poder marcadas por el sistema patriarcal hacen que su entrada sea muy difícil por los propios estereotipos sexistas, los niveles de competitividad y la diferente concepción de liderazgo atribuida legítimamente a los hombres que son los que ostentan y han ostentado el poder. La mujer líder atrae la

\footnotetext{
${ }^{25}$ Véase entre otras VALCÁRCEL y De QUIROS, Amelia (1997). La política de las mujeres. Madrid. Cátedra. COBO BEDIA, Rosa (2000). 'Política Feminista y Democracia Paritaria'. Leviatán, Revista de hechos e ideas $\mathrm{n}^{\circ}$ 80, pág. 85-99. COBO BEDIA, Rosa (1993). 'Mujer y Poder'. Revista Internacional de Filosofía Política, no 1. Pág. 165-177. AMORÓS PUENTE, Celia (1990). Mujer y participación política. Pp. 197-115 en Participación política de las mujeres, compilado por J. Astelarra. Madrid: Centro de Investigaciones Sociológicas. RUBIO CASTRO, Ana (1997). Feminismo y Ciudadania. Sevilla: Instituto Andaluz de la Mujer.

${ }^{26}$ Capo Jordi (1992) señala que en las elecciones municipales de 1983 la cualificación de las concejalas, por sus estudios o profesión, era notablemente superior a la de los hombres
} 
atención hacia su vida personal y es juzgada por otros aspectos que no tienen que ver con su participación y competencia política, se tiene más en cuenta su presencia física, su biografía personal, el modo en el que viste, se maquilla, habla, se mueve...o cuando no actúan con comportamientos propios de su género (Baxter y Lansing, 1983). Margaret Thatcher, Angela Merkel o $\mathrm{M}^{\mathrm{a}}$ Teresa Fernández de la Vega son claros ejemplos. Las expectativas unidas a los estereotipos por ser mujeres les confiere un significado y una interpretación social diferente al de los hombres. Es cierto que la participación en política no supone un espacio propio para las mujeres, pero es innegable que cuando las mujeres entran en este área cambian el concepto de lo político con su presencia y sus propuestas transformadoras (Del Valle Murga Maria Teresa, $2001)^{27}$.

Por otro lado, la baja participación de las mujeres en las altas esferas de poder y mucho menos en las zonas rurales, implica que tengamos pocos referentes y muchos de ellos con el desempeño de valores y comportamientos masculinos a la hora de ejercer el liderazgo. Aún así, ciertas investigaciones ponen de manifiesto la existencia de una forma diferente de ejercer el liderazgo en las mujeres basado en las emociones, la interacción, la comunicación y el consenso (Blázquez Vilaplana, Belén, 2005).

El poder y la autoridad están relacionados con lo masculino, posee, en palabras de Foucault $^{28}$, características de circularidad y dinamismo que le confiere ejecutarlo a través de las relaciones, esto muestra a las mujeres capacidades y potencialidades para poder ejercerlo a pesar de estar sistemáticamente invisibilizado. Como nos expone Fátima Cruz, 'en la medida que las mujeres tienen conciencia de su propio poderío, pueden llegar a negociar y decidir por sí mismas y también con los hombres ${ }^{29}$. Es por ello que toma tanta relevancia el hecho de tomar conciencia del propio liderazgo para ejercerlo. Según Marcela Lagarde 'las mujeres construyen poder simbólico, sin embargo al no deconstruir la parte de negatividad que se asigna al poder ejercido por mujeres y desdecir de su autoridad, se hace un doble juego que equivale a querer el poder y cuando se logra, se desmonta o es usado subrepticiamente y no es legitimado en el lenguaje, ni en los distintos ámbitos donde están, o en las maneras que se usa el poder

\footnotetext{
${ }^{27}$ En POLO GONZÁLEZ, María Eugenia y SANTIAGO BARNÉS, Jorge (2011). Liderazgo, Mujer y Política. Salamanca: Amarú.

${ }^{28}$ FOUCAULT, M (1999). Estrategias de Poder. Barcelona: Paidos.

${ }^{29}$ CRUZ SOUZA, Fátima (2009). 'Empoderamiento y participación social de las mujeres en el medio rural'. Revista Agricultura Familiar en España. Pág. 110-115
} 
de la autoridad'. Y la autoridad de las mujeres es imprescindible para avanzar tanto en política como en desarrollo personal propio (Murano Luisa) ${ }^{30}$.

Otros aspectos que influyen en el nivel de participación son la conciliación de la vida familiar y pública en donde las mujeres, a diferencia de los hombres, padecen de la doble jornada que hace que su disponibilidad sea mucho más baja para participar en la vida pública ${ }^{31}$. A la doble jornada diaria de las mujeres, la laboral y la familiar, la política supone, a menudo, una tercera jornada (Norris Pippa y Franklin Mark, 1997). No es así para los hombres ya que ellos tienen, en general, resueltas las obligaciones familiares (Chicano, 2004).

\section{1.- Impacto de las políticas feministas en la adquisición de derechos para las mujeres en el ámbito local.}

En este sentido me sirve de referencia para este apartado el estudio de la Federación Española De Municipios y Provincias (FEMP) de $2007^{32}$ sobre el impacto de la entrada en vigor de la Ley Orgánica 3/2007 para la Igualdad efectiva de Mujeres y Hombres en la representación de las mujeres en el ámbito de la política local (la Ley Orgánica 3/2007 para la Igualdad efectiva de Mujeres y Hombres establece en el Título segundo capítulo primero el principio de presencia equilibra de de mujeres y hombres en las listas electorales y en los poderes públicos. Además contempla las pautas de actuación en igualdad que deben seguir los poderes públicos y los instrumentos para la integración y la aplicación de la trasversalidad de género) Según este trabajo, debemos hablar de tres conceptos básicos desde la teoría de género en cuanto a la presencia y posición de mujeres y hombres en los organismos de decisión política. El primero es la segregación vertical que delimita el acceso desigual de las mujeres en las estructuras de poder. A medida que se avanza en la jerarquía de poder, la presencia de mujeres disminuye respecto a los hombres; es el Techo de cristal (Hymowitz y Schellhardt:

\footnotetext{
${ }^{30}$ Citada en LAGARDE Marcela (1999). Claves Feministas para el poderío y la autonomía de las Mujeres. Sevilla: Instituto Andaluz de la Mujer. Pág. 87

31 Véase concepto de 'tiempo circular' en las mujeres en DURÁN HERAS Ma Ángeles, ROGERO GARCÍA Jesús (2009). La investigación sobre el uso del tiempo. CIS. Pág. 215.

${ }^{32}$ Para ampliar información véase el estudio completo FEDERACIÓN ESPAÑOLA DE MUNICIPIOS Y PROVINCIAS (FEMP). 2007. Estudio del impacto de la Ley Orgánica 3/2007 para la igualdad efectiva de mujeres y hombres en la representación de las mujeres en el ámbito de la política local. Madrid: FEMP.
} 
1986) ${ }^{33}$ que padecen las mujeres especialmente a nivel local. El segundo es la segregación horizontal que hace referencia al tipo de responsabilidad asignada a las mujeres que están presentes en los mecanismos de decisión que hace que las mujeres ocupen puestos tradicionalmente femeninos como son Servicios Sociales, Igualdad y Mujer, Sanidad, o Festejos; son las llamadas 'concejalías blandas' que a nivel simbólico y funcional tienen una repercusión directa en el reparto presupuestario. Sin embargo con mucha frecuencia las mujeres aceptan estas concejalías de buena gana e incluso las eligen por ser más accesibles a ellas ya que les permiten compaginarlo con su vida familiar y además constituyen campos en los que se sienten más cómodas. El intento de conciliar se convierte en el primer obstáculo para la participación en la política local de las mujeres (Palenzuela Pablo y Cruces Cristina, 2009). Por último la paridad constituye el mecanismo principal de equidad en la representación política de mujeres y hombres. Según lo que establece, ningún sexo tendrá una representación menor al 40\% y más del $60 \%$ y las candidaturas deberán estar conformadas conforme a esa horquilla $^{34}$. Estas proporciones deben ser respetadas tanto en el conjunto de la lista

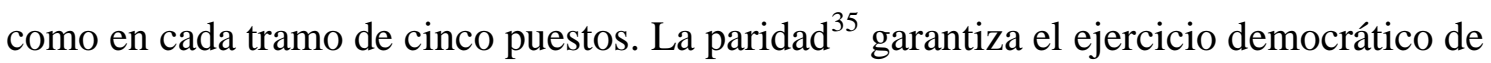
la igualdad entre hombres y mujeres y contribuye al cambio de roles de género tradicionales aportando un modelo igualitario ${ }^{36}$.

La primera vez que se presentó en España una proposición de ley instando al incremento de la presencia de las mujeres en los cargos públicos fue en 1996, bajo el primer gobierno del PP. El 8 de abril de 2002 se presentaron en el Congreso tres proposiciones de ley para reformar la Ley Orgánica del Régimen Electoral General con el objetivo de equilibrar la presencia de hombres y mujeres en las listas electorales. Las iniciativas contaron con el apoyo de todos los partidos de la oposición y el rechazo del PP. Finalmente, el 15 de marzo de 2007, con el apoyo favorable de todos los partidos y la abstención del PP, el Congreso aprobó la Ley de Igualdad 3/2007. Esta ley vela por el cumplimiento obligatorio para los municipios con más de 5.000 habitantes, y a partir de 2011 lo es también para los municipios de más de 3.000 habitantes. Sin duda, el año

\footnotetext{
33 Acuñamiento del término en el informe sobre mujeres ejecutivas publicado por Hymowitz y Schellhardt en el Wall Street Journal en 1986.

${ }^{34}$ Para las distintas modalidades de cuotas puede consultarse la web del Instituto para la Democracia y la Asistencia Electoral (IDEA): http://www.quotaproject.org.).

${ }^{35}$ Fuente Tània Verge Mestre. Cuotas voluntarias y legales en España. La paridad a examen. En Revista Española de Investigaciones Sociológicas (Reis) N. ${ }^{\circ}$ 123, 2008, pp. 123-150
} 
2007 será un año crucial para la participación política de las mujeres en España ${ }^{37}$, aunque es de destacar que ya anteriormente dentro de los partidos se contemplaban medidas que les obligaban a incluir a mujeres en sus listas. El partido pionero fue el PSOE que en 1988 aprueba que el 25\% de sus listas electorales esté compuesto por mujeres, les seguirá Izquierda Unida con el 35\% y otros partidos minoritarios.

El informe de la FEMP concluye que entre 2003 y 2007 el porcentaje de concejalas en el conjunto español subió de un $25,7 \%$ al $30,8 \%$ y que los municipios andaluces de menos de 5.000 habitantes pasaron del 32,08\% al 37,75. En cuanto a las alcaldesas los datos son del $13,1 \%$ al $14,8 \%$, lo cual corrobora lo positivo del impacto de las políticas de igualdad.

\section{2.- El papel del Asociacionismo en el mundo rural.}

El importante papel que tienen las asociaciones de mujeres en la transformación de realidades y en la creación de ciudadanías responsables e igualitarias ha sido referenciado por diversos trabajos (Maquieira, 1995; Del Valle, 2001; Alba, 2003; Murillo y Rodríguez, 2003; Franco, Gilló y Sánchez, 2005; Valiente, 2005; Ortbals, 2010; Infante, 2011). Éstos han destacado su contribución a los procesos de inclusión social (Sipi, 2000) y de solidaridad comunitaria al proporcionar servicios de bienestar y apoyo mutuo (Corona, 2004) ${ }^{38}$. Constituyen un elemento básico para la participación ciudadana y el cambio social en lo público al permitir crear un espacio en el que poner en marcha estrategias de acción colectiva (Murillo y Rodríguez, 2003) que contrarreste al propio modelo patriarcal rural en donde todavía persisten grandes desequilibrios. Además las asociaciones de mujeres tienen un papel importantísimo al hacer también visibles las situaciones de discriminación hacia otras mujeres y construir "espaciospuente" que contribuyen al empoderamiento de las demás mujeres (Del Valle Teresa, 2001).

\footnotetext{
${ }^{37}$ Vuelve a destacar España como uno de los cinco países (junto a Bélgica, Francia, Bosnia Herzegovina y Costa Rica) cuya cuota se compromete con la democracia paritaria, es decir, con una representación

${ }^{38}$ En Sánchez-Muros, Sonsoles Patricia \& Jiménez Rodrigo, Maria Luisa. (2013). Mujeres rurales y participación social: análisis del asociacionismo femenino en la provincia de Granada (España). Cuadernos de Desarrollo Rural, 10 (72), 223-242.
} 
El modelo patriarcal junto a las características estructurales del medio rural han limitado tradicionalmente la participación social de las mujeres (Palenzuela y Cruces, 2011). La manera en que se han relacionado las mujeres rurales ha cambiado mucho en los últimos años y no pueden ser tratadas sin tener en cuenta las propias características de lo rural, el modelo de familia y la diversificación económica (Farah, 2008). Las mujeres que permanecen en sus pueblos se enfrentan al dilema de reproducir el papel "ama de casa" u optar a empleos eventuales, precarios y de economía sumergida en el sector agroindustrial, el sector servicios, el textil y manifactura sobre todo (Sampedro, 2007). El incremento de la población activa femenina rural y de sus niveles educativos, sobre todo, entre las jóvenes, deriva en una fuerte inadecuación funcional entre sus aspiraciones laborales y la formación real de los mercados locales de trabajo, y esto motiva una creciente emigración femenina (Díaz Méndez, 2006). Es en este escenario donde las asociaciones de mujeres se sitúan como un instrumento de cambio y futuro para las mujeres rurales al formarse como una "nueva herramienta" para participar en su espacio rural y en sus procesos de cambio ${ }^{39}$.

A partir de los años 90, desde las instituciones se les dio apoyo a las organizaciones de mujeres para trabajar el empoderamiento. Claro es el ejemplo de la apuesta del Instituto Andaluz de la Mujer hacia programas destinados a promover el asociacionismo y el empoderamiento en las asociaciones de mujeres andaluzas como medio para desarrollar sus potencialidades de trasformación. En el informe de 1989 del Instituto Andaluz de la Mujer se contabilizaron 152 asociaciones de mujeres y en el de 2011 ya alcanzaban las 2.102 entre asociaciones y federaciones (IAM., 2012).

Por su importancia a nivel provincial y regional voy a destacar el Consejo Andaluz de Participación de las Mujeres y la Red de Mujeres Rurales y Urbanas y el Programa ASOCIA, estas iniciativas parten desde las instituciones públicas y son ejemplos de vertebración de la participación de las mujeres y de la creación de redes entre ellas. A continuación pasaré a explicarlos resumidamente.

El Consejo Andaluz de Participación de las Mujeres se creó en $2011^{40}$ para canalizar a través de las representantes provinciales, las opiniones de las mujeres

\footnotetext{
39 En Sánchez-Muros, Sonsoles Patricia \& Jiménez Rodrigo, Maria Luisa. (2013). Mujeres rurales y participación social: análisis del asociacionismo femenino en la provincia de Granada (España). Cuadernos de Desarrollo Rural, 10 (72), 223-242.
} 
andaluzas. Sus principales funciones son contemplar las propuestas y aportaciones del movimiento asociativo en relación con las políticas autonómicas de igualdad de género, velar por el incremento de la participación de las mujeres en los procesos públicos y privados de toma de decisiones, prestar asesoramiento a la administración y promover la difusión de los valores de la igualdad entre la sociedad andaluza. Este consejo agrupa a los Consejos Locales y crea una red a nivel andaluz sin precedentes.

En Andalucía existen un total de 89 Consejos Locales, destacando Granada con $24^{41}$. El Consejo Comarcal de la Mujer de la comarca Guadalteba es el quinto más antiguo (1996). Algunos consejos tienen el carácter de supramunicpal, como es el caso del CCM Guadalteba que comprende ocho municipios.

El Programa ASOCIA ${ }^{42}$ nace con el objetivo de impulsar la participación de las Asociaciones de Mujeres y configurar la participación de las mujeres en los espacios políticos, consultivos y decisorios, así como en los diferentes ámbitos de la sociedad a través de las entidades en las que se integran y que las representan. Entre sus objetivos está el fortalecimiento del sentimiento identitario en las asociaciones y federaciones de mujeres, conformar y consolidar una red activa de asociaciones que interactúen entre ellas $^{43}$, con el Instituto Andaluz de la Mujer y con los Centros Municipales de Información a la Mujer, consolidar el sistema de comunicación de las asociaciones de mujeres de Andalucía con el Instituto Andaluz de la Mujer y determinar las líneas de actuación y participación de las entidades de mujeres en el Programa.

\footnotetext{
${ }^{40}$ La Ley 12/2007, de 26 de noviembre, para la Promoción de la Igualdad de Género en Andalucía, en su artículo 62 crea el Consejo Andaluz de Participación de las Mujeres. Mediante el Decreto 154/2011, de 10 de mayo, se regula y configura como un órgano colegiado de participación de las organizaciones de mujeres en las políticas de igualdad de género de la Junta de Andalucía. Consultar la Web I.A.M.: http://www.juntadeandalucia.es/institutodelamujer/index.php/participacion-y-asociaciones/el-consejoandaluz-de-participacion-de-las-mujeres

${ }^{41}$ INSTITUTO ANDALUZ DE LA MUJER (2010). Los Consejos Locales de la Mujer en Andalucía. Diagnóstico de la situación.

42 Fuente web IAM: http://www.juntadeandalucia.es/institutodelamujer/index.php/participacion-yasociaciones/programa-asocia

${ }^{43}$ Reseñar que las Asociaciones de Mujeres de la comarca están adscritas a este programa.
} 
Respecto a las mujeres rurales en particular destaca la Red de Mujeres Rurales y Urbanas $^{44}$. Se creó como un espacio común en el que las organizaciones de mujeres de zonas rurales y urbanas interaccionaran y crearan sinergias entre ellas con el objetivo de crear un Plan de Acción conjunto de avance hacia los derechos de las mujeres andaluzas. Los objetivos específicos son coordinar estrategias y sumar fortalezas para conseguir objetivos comunes, a la vez que debatir y analizar temáticas relevantes planteadas por las asociaciones y federaciones de mujeres urbanas y rurales, en el marco del principio de Igualdad de Oportunidades entre mujeres y hombres.

Otros ejemplos de asociacionismo que parten de la propia voluntad de agruparse son la Confederación de mujeres rurales, la Federación de mujeres y familias del ámbito rural y Familias del Ámbito Rural (AMFAR), la Asociación de Mujeres Rurales de Málaga (ADEMUR-Málaga) federadas en la Federación de Mujeres Rurales de Andalucía (FADEMUR) ${ }^{45}$.

\section{3.- Liderazgo y ostentación del poder de las mujeres en Andalucía.}

En Andalucía se ha estudiado la evolución que referencia cómo las mujeres se han ido incorporando a la vida pública andaluza y ponen de relieve el liderazgo obtenido por las mujeres que han ido ganando terreno en la esfera política ${ }^{46}$.

La acción institucional vuelve a constituir un mecanismo de acción imprescindible para facilitar la participación de las mujeres rurales en todas las esferas como ponen de relieve los diferentes informes y estudios abalados por el Instituto

\footnotetext{
${ }^{44}$ Con motivo del Día Internacional de la Mujer se procedió a la firma de un Protocolo de colaboración entre las asociaciones y federaciones de mujeres de Andalucía de las zonas rurales, las de las zonas urbanas, la Consejería de Agricultura y Pesca y la Consejería para Igualdad y Bienestar Social para la puesta en marcha de la Red de Mujeres Rurales y Urbanas.

${ }^{45}$ Para más información visitar las webs: http://www.ceres.org.es/home.php, http://mujerrural.com/, http://www.fademur.es/

${ }^{46}$ Para ampliar información sobre liderazgo de mujeres véase entre otras VALCÁRCEL y De QUIROS, Amelia (1997). La política de las mujeres. Madrid. Cátedra. POLO GONZÁLEZ, María Eugenia y SANTIAGO BARNÉS, Jorge (2011). Liderazgo, Mujer y Política. Salamanca: Amarú. SÁNCHEZ HERNÁNDEZ, María F. 2003. 'Liderazgo Político de Mujeres. Desde la Transición hacia la Democracia Paritaria'. Sevilla: Instituto Andaluz de la Mujer.
} 
Andaluz de la Mujer ${ }^{47}$. Encontramos de nuevo pocos estudios en referencia al ámbito local rural. Si redundamos en los datos a nivel regional y en los informes publicados vemos como la presencia de mujeres en los órganos de decisión ha ido aumentando. Por ejemplo, en cuanto a las parlamentarias andaluzas, la evolución de la representación de mujeres en el parlamento andaluz cumple en la actualidad con las pautas de paridad. Por cada 10 representantes, 5,5 son parlamentarios y 4,5 parlamentarias. En 1982, por cada 20 representantes, 19 eran parlamentarios y 1 parlamentaria. El número de alcaldesas andaluzas suponen un $19,48 \%$ respecto al total de alcaldías. Las provincias que más alcaldesas tienen son Granada y Córdoba (el 29,33\% de las alcaldías están ocupadas por mujeres) y la que menos es Sevilla con un 12,38\% respecto al total. También se ha incrementado considerablemente el número de diputadas. No podemos decir lo mismo de Consejo Económico y Social (CES), Tribunal y Cámara de Cuentas donde sólo se consigue un equilibrio entre mujeres y hombres en los órganos unipersonales que representan a Andalucía a nivel estatal. El resto de órganos del CES la proporción de mujeres dista mucho de acercarse a indicadores paritarios. En la Comisión Permanente del CES en Andalucía por cada seis hombres sólo encontramos a una mujer. El Tribunal de Cuentas Andaluz sólo cuenta con 1 consejera respecto a 11 hombres y la Cámara de Cuentas también cuenta sólo con una representación entre las personas Consejeras de 1 mujer respecto a 6 hombres en su composición. En el Tribunal Superior de Justicia de Andalucía, la proporción de mujeres es del 26,1\%, porcentaje que apenas ha variado en los últimos cuatro años. ${ }^{48}$

\footnotetext{
${ }^{47}$ Véase web del IAM

${ }^{48}$ INSTITUTO ANDALUZ DE LA MUJER (2010). Realidad de mujeres y hombres en Andalucía.
} 


\section{Capítulo 3.- El criterio de Interseccionalidad}

Es de vital importancia tener en cuenta el criterio de interseccionalidad para no olvidarnos de la singularidad de cada uno de los colectivos que conforman las mujeres. Está claro que existen características generales a las mujeres rurales, pero no debemos olvidar, que debemos de partir de un enfoque en el que se contemple la diversidad que las hace también diferentes unas de otras; una mirada amplia que contemple a todos los colectivos existentes. Al igual, la construcción de la ruralidad debe implicar un análisis en el que se incluya la perspectiva de género junto con otros criterios y categorías de análisis como son la raza, la edad, la orientación sexual, la discapacidad, el lugar de procedencia, etc, Pero también habría que profundizar en elementos que son específicos de la ruralidad y que pueden intervenir en la vida de las mujeres, en unos casos limitándolas -como son el alejamiento de zonas de mayor desarrollo cultural, menores opciones laborales, mayor control de la vida privada y dependencia de las redes familiares- y en otros facilitando redes de apoyo, comunicación, compartir emociones, una visión diferente del medioambiente, etc.

El enfoque de la intersecionalidad se hace necesario para analizar y tener en cuenta las estructuras de poder que están implícitas no solo a niveles generales sino también a niveles más particulares haciendo referencia a la heterogeneidad de las mujeres y de otros grupos sociales para ver la naturaleza, las causas de las desigualdades y las nuevas relaciones de género que se establecen (Little, 2002).

El propio feminismo ya reconoció esta carencia y a raíz de las críticas que desde el feminismo afroamericano ${ }^{49}$ se vertieron en los años ochenta, se introdujo en el análisis y en la agenda feminista. Las políticas públicas tuvieron y tienen la obligación de velar por los intereses dispares de las minorías partiendo de estos criterios (Barrere Unzueta $\mathrm{M}^{\mathrm{a}}$ Ángeles, 2010). Merece la pena mencionar el término en palabras de la mujer que lo acuñó: Crenshaw define la interseccionalidad como la expresión de un 'sistema complejo de estructuras de opresión que son múltiples y simultáneas. En su marco teórico, la subordinación interseccional es, a menudo, la consecuencia de un

\footnotetext{
49 Kimberlé Williams Crenshaw acuñó el término en 1995 publicando en 1989: «Demarginalizing the Intersection of Race and Sex: A Black Feminist Critique of Antidiscrimination Doctrine, Feminist Theory and Antiracist Politics». También destacan Elizabeth Spelman (1988), Patricia Hill Collins (1998, 2000, 2006), Valerie Purdie-Vaughns y Richard P. Eibach (2008)
} 
factor de discriminación que, al interactuar con otros mecanismos de opresión ya existentes crean, en conjunto, una nueva dimensión de desempoderamiento'. En este sentido, la incorporación de la interseccionalidad al mainstreaming de género, refuerza precisamente el largo debate del movimiento feminista de que las mujeres no son un grupo homogéneo.

En el ámbito de las mujeres rurales no se ha trabajado en exceso el concepto de interseccionalidad, esperamos que en trabajos posteriores se puedan vislumbrar los aspectos hereogeneos de las mujeres en los contextos rurales.

'Solo reconociendo la diversidad y la diferencia y aceptando el carácter múltiple y posiblemente conflictivo con el que se conforman las identidades, es posible crear vínculos politicos entre las mujeres' Sonya O. Rose ${ }^{50}$

${ }^{50}$ Véase ROSE O. Sonya. 2012. ¿Qué es Historia de Género? Madrid: Alianza Editorial. Pág. 41 


\section{Capítulo 4.- Hipótesis y Metodología}

Parto de las hipótesis de que son las asociaciones de mujeres las que promueven la participación, el liderazgo y el empoderamiento en las zonas rurales, que los patrones de tradicionales de género en la acción pública marcan en gran medida las formas de actuación de las mujeres y que las políticas públicas de igualdad favorecen su incorporación al espacio público. Otra de las hipótesis es que el Consejo Comarcal de la Mujer ha supuesto un mecanismo excepcional y de repercusión favorable en la vida de las mujeres, permitiendo deliberar y decidir conjuntamente al tejido asociativo y a las instituciones.

La recogida de información para la presente investigación se ha realizado a través de metodología cuantitativa y cualitativa que a continuación pasaré a explicar. El método utilizado es el método descriptivo ya que no pretendo hacer un estudio comparativo sino un análisis detallado sobre los factores que inciden en la participación y el liderazgo de las mujeres rurales en esta comarca.

La fase metodológica se ha realizado a través de la investigación bibliográfica, la recogida de datos para el análisis estadístico y el trabajo de campo cualitativo para recoger testimonios mediante entrevistas en profundidad. La información sacada de las entrevistas y del análisis cuantitativo nos dará una radiografía del progreso y los cambios que se han producido en la participación y el liderazgo de las mujeres de esta zona. Analizaré el significado en el imaginario colectivo de las mujeres rurales en la participación desde las instancias de políticas municipales y asociativas y ver el papel que se otorgan a sí mismas en la contribución del cambio y el desarrollo de sus vidas. A continuación se hace una aclaración de los instrumentos utilizados:

Para la investigación bibliográfica he acudido a fuentes de estudios de teóricas feministas y a los informes oficiales de organismos institucionales como la revisión de estudios publicados referentes a la participación de las mujeres rurales.

La recogida de datos estadísticos se ha realizado mediante la consulta de fuentes estadísticas y documentos oficiales tales como el Instituto Nacional de Estadística (INE), Instituto de Estadística de Andalucía (IEA), Sistema de Información Territorial de Andalucía (SIMA), Observatorio Electoral desde la Perspectiva de Género de la 
Federación Andaluza de Municipios y Provincias (FAMP), Federación Española de Municipios y Provincias (FEMP), Boletines Oficiales de la Provincia (BOPs), así como visitas in situ al Archivo Municipal de Málaga, Archivo general del Consorcio Guadalteba, Archivo Centro de Información a la Mujer del Consorcio Guadalteba y Archivo de la Federación de Asociaciones de Mujeres Peñarrubia.

Esta recogida ha servido para averiguar el índice de participación política de las mujeres como representantes de partidos, las listas electorales desde el año 1995 al 2011, el índice de participación política en las estructuras de poder como alcaldesas y/o concejalas, las estadísticas de participación en listas política electoral y la existencia de listas igualitarias

Para el análisis del Consejo Comarcal de la Mujer he acudido al archivo del Consorcio Guadalteba y he analizado las actas del mismo desde su creación, además de la información recabada con la técnica del CIM y la consulta de los estatutos de creación que pueden consultarse en el Anexo número 2

En el trabajo de campo he utilizado una metodología cualitativa a través de entrevistas en profundidad a mujeres pertenecientes a asociaciones de mujeres, concejalas y alcaldesas. Para ello me he trasladado a los diferentes pueblos de la comarca. Con este tipo de entrevista he obtenido datos muy valiosos ya que es un instrumento que permite reformular nuevos planteamientos conforme a la propia dinámica del diálogo cercano que se establece en ella. Para diseñarla he tenido en cuenta un guion fijado para asociaciones y otro para políticas ${ }^{51}$. Se ha garantizado el anonimato para no inhibir sus opiniones, y su duración ha tenido un promedio de una hora y media. ¿Cómo han contribuido las mujeres a mejorar sus propias vidas y las vidas de las demás mujeres a través de la participación y el liderazgo? Para ello se ha incitado en ellas a dar la opinión sobre el tiempo que llevan participando tanto en política municipal como desde las asociaciones, cómo fueron reclutadas, los motivos que les llevaron a participar, si ostentan o han ostentado algún cargo (concejalía, alcaldía o miembro de la junta directiva de asociación y cuál), cómo se sienten participando, cuál es la relación con sus compañeros y compañeras de partido y en las asociaciones, si sus opiniones eran y son tenidas en cuenta, valoradas, las facilidades/obstáculos que se encuentran para participar y ejercer su liderazgo, la

\footnotetext{
${ }^{51}$ Ver Anexo 4
} 
importancia de la presencia de las mujeres rurales en la vida política-asociativa, las oportunidades y/o dificultades que se encuentran, iniciativas de igualdad concretas que se llevan a cabo desde las tres instancias de participación que se contemplan, si poseen un compromiso definido con la igualdad y con la mejora de la vida de las mujeres, las actividades que se llevan a cabo tanto desde los ayuntamientos como desde las asociaciones de mujeres en materia de igualdad de género, el protagonismo de las asociaciones de mujeres para crear conciencia de género en la política municipal y cómo valoran el Consejo Comarcal de la Mujer y si se consideran feministas ${ }^{52}$.

La muestra de mujeres elegidas ha sido 22 en total, 11 pertenecientes a partidos políticos y 11 a asociaciones de mujeres. El rango de edad se sitúa desde los 24 a los 70 años y el nivel formativo abarca desde sin estudios a licenciatura y son mujeres representantes de partidos políticos (concejalas y alcaldesas), mujeres de asociaciones de mujeres, mujeres que están en política y mujeres que la abandonaron.

Los indicadores que tengo en cuenta en la investigación partiendo de la edad y la formación son: el grado de autonomía, el grado de ruptura y/o reproducción de los papeles tradicionales de género, grado de autoestima y empoderamiento, grado de concienciación feminista y grado de concepto de igualdad que poseen las mujeres entrevistas. También he intentado identificar los motivos para participar tanto en política desde los ayuntamientos como desde las asociaciones de mujeres, la percepción de liderazgo y el cómo lo ostentan así como las acciones que llevan a cabo para mejorar la vida de las mujeres de su entorno.

Algunas de las dificultades que he encontrado son la inexistencia de estudios previos sobre la participación política y el liderazgo de las mujeres en esta comarca, lo que me ha llevado a partir prácticamente de cero en cuanto a la elaboración del material para el análisis. Por otro lado, no he podido conseguir datos municipales desglosados por sexo en cuanto el número de votantes, para ello he recurrido a varias fuentes y en ninguna he podido obtener esta información ya que los datos son facilitados en desglose por sexo desde el 2007 pero a nivel provincial. Los Boletines Oficiales de la Provincia solo aparecen digitalizados a partir de 2003, por lo que para consultar los anteriores he tenido que solicitarlo y trasladarme al Archivo Municipal de Málaga. Y por último el

\footnotetext{
${ }^{52}$ Véase anexo 2: Entrevistas
} 
difícil acceso a entrevistar a mujeres que abandonaron la política debido a que sus partidos ya no se presentan a las elecciones. 


\section{III.- LA COMARCA DEL GUADALTEBA}

Con una superficie de 762,58 Km2, e integrada por los municipios de Almargen, Ardales, Campillos, Cañete la Real, Carratraca, Cuevas Del Becerro, Sierra de Yeguas y Teba, localizamos la Comarca rural del Guadalteba. Esta zona se encuentra situada al Norte de la provincia de Málaga, entre los términos municipales de Ronda, Álora y Antequera.

Mapa 1. Provincia de Málaga dividida por comarcas

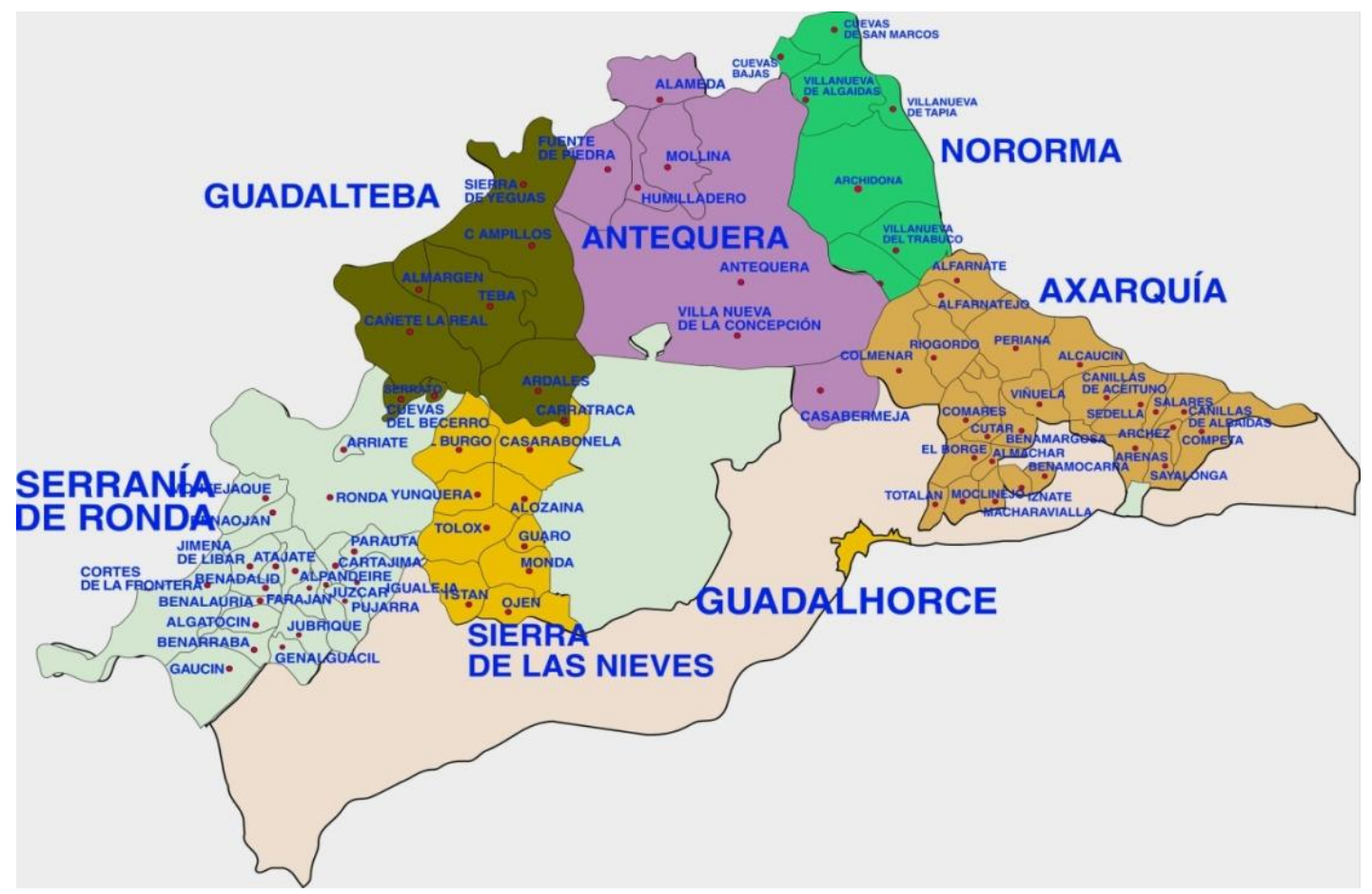

Cuenta con una población total de $25.174^{53}$ habitantes equiparada por sexos (49,94\% mujeres y 50,05 hombres). El municipio más poblado es Campillos (8.677) que duplica en número de habitantes al municipio que le sigue en importancia, Teba, siendo el más pequeño y menos poblado Carratraca.

\footnotetext{
${ }^{53}$ Datos del año 2011, fuente IEA (Instituto de Estadística de Andalucía)
} 

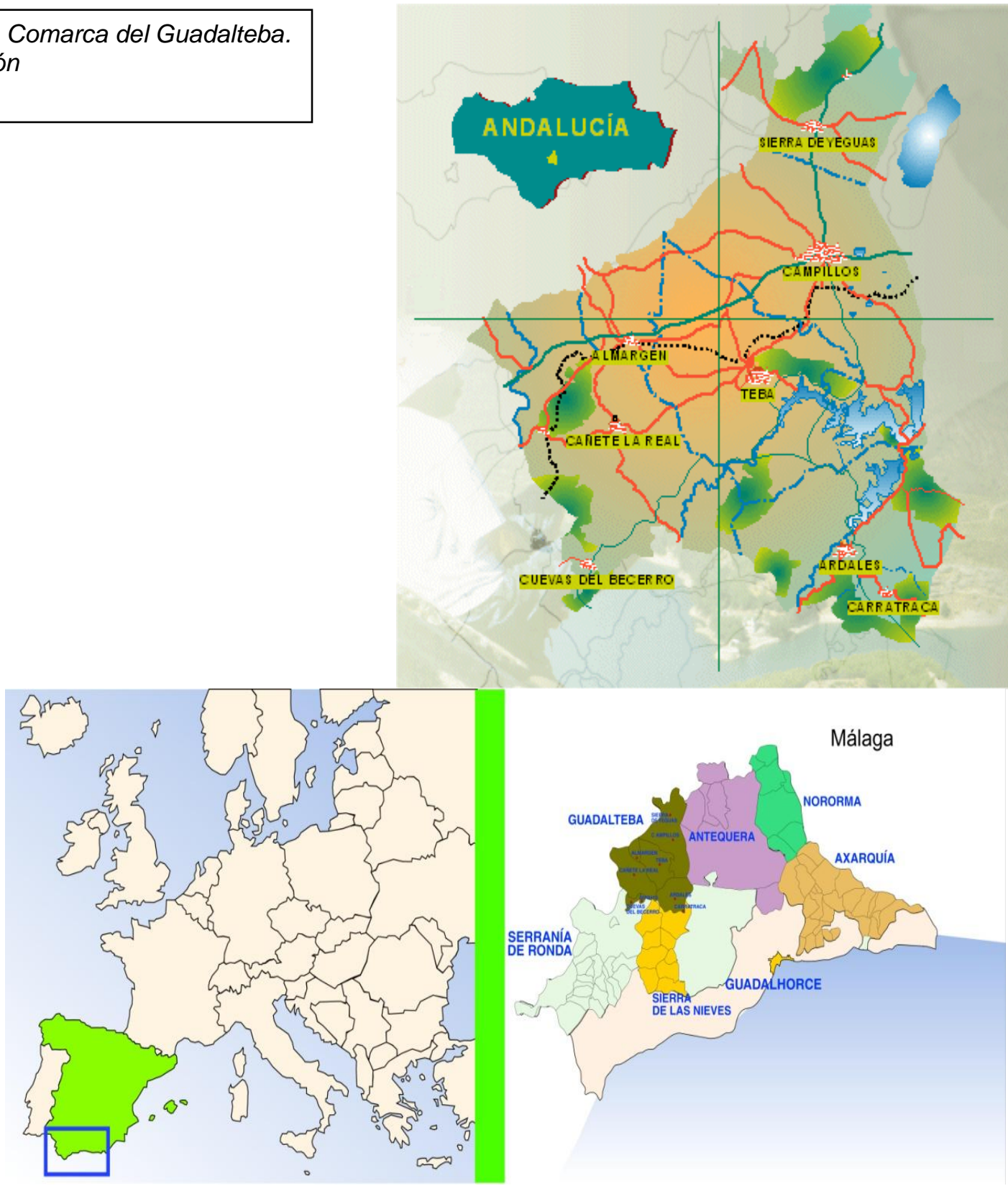

Los municipios que componen la Comarca del Guadalteba se constituyeron en Consorcio en el año 1993 junto con la Diputación Provincial de Málaga. Su objetivo era la prestación mancomunada de servicios públicos de carácter local y la ejecución de una política de desarrollo global territorial. Cabe decir que este proceso de adhesión de los pueblos ha sido gradual y que en cuanto a políticas de igualdad, el ámbito de actuación también ha abarcado a la Entidad Local Autónoma de Serrato ${ }^{54}$ a pesar de no pertenecer a la comarca del Guadalteba desde el 2011.

\footnotetext{
${ }^{54}$ Entidad Local Autónoma perteneciente a la comarca de Ronda
} 


\section{Capítulo 1.- Población, nivel de estudios y mercado de trabajo}

Paso a dar algunos datos sobre población, nivel de estudios y mercado de trabajo los cuales se presentan desagregados para asegurar la interpretación de hombres y mujeres en los tres planos escogidos. Quiero destacar que han sido consultados otros datos como el IRPF, etc. pero al no haber datos desglosados por sexo no se han tenido en cuenta en el estudio.

\section{1.- Datos poblacionales}

Como puede observarse en la siguiente tabla, las poblaciones de los diferentes municipios están bastante equiparadas en cuanto al número de mujeres y hombres, siendo el número total de hombres ligeramente mayor que el de mujeres, 12.531 hombres y 12.643 mujeres. Ver Anexo 3 para los grupos de edad

\section{Población según sexo}

\begin{tabular}{|c|c|c|c|}
\hline & MUJERES & HOMBRES & TOTAL \\
\hline ALMARGEN & 999 & 1.046 & 2.045 \\
\hline ARDALES & 1.284 & 1.304 & 2.588 \\
\hline CAÑETE LA REAL & 899 & 913 & 1.812 \\
\hline CAMPILLOS & 4.330 & 4.347 & 8.677 \\
\hline CARRATRACA & 404 & 412 & 816 \\
\hline CUEVAS DEL BECERRO & 860 & 844 & 1.704 \\
\hline SIERRA DE YEGUAS & 1.735 & 1.753 & 3.488 \\
\hline TEBA & 2.020 & 2.024 & 4.044 \\
\hline TOTAL & 12.531 & 12.643 & 25.174 \\
\hline
\end{tabular}




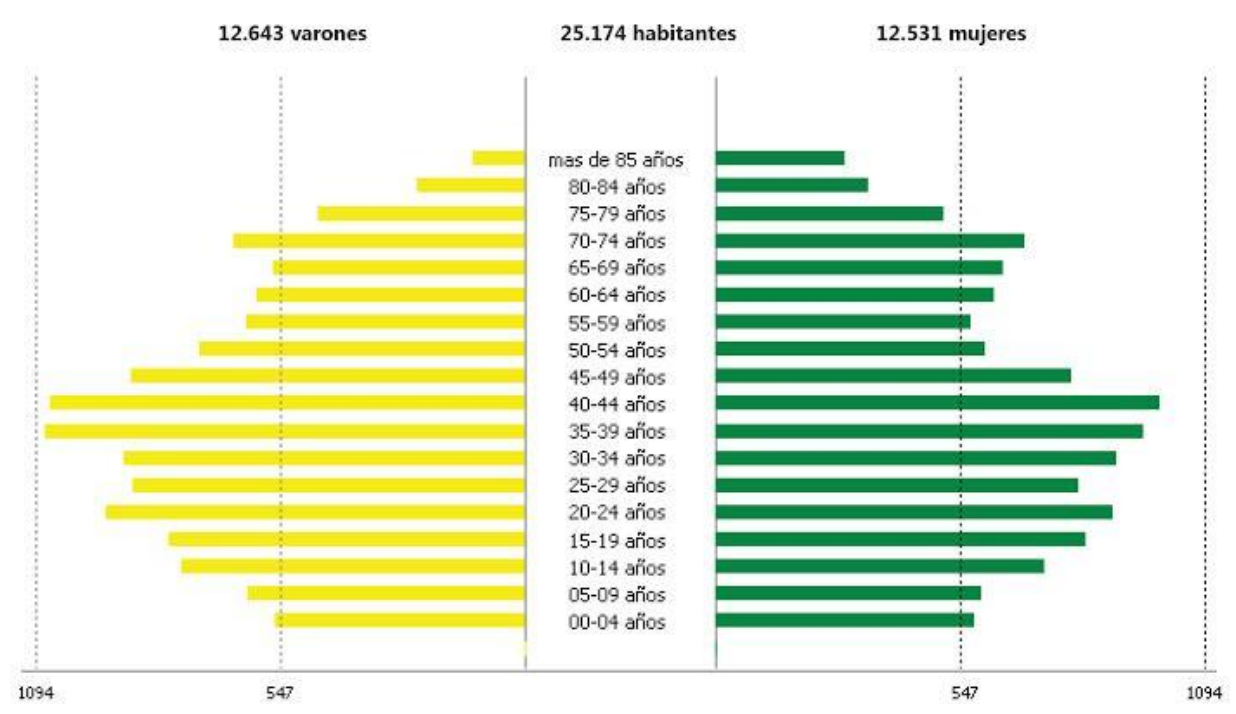

La pirámide de población de Guadalteba muestra la forma de campana en la que encontramos una base más estrecha que en los escalones centrales. Esto significa que existe un importante envejecimiento de la población y que la natalidad tiene unos índices muy bajos. Por otro lado, si nos fijamos en la población mayor de 75 años vemos una alta esperanza de vida. La estructura de la población en función del sexo, presenta una proporción muy similar entre el número de hombres y mujeres Sin embargo, esta similitud se ve modificada a partir del grupo de edad de los 65 años, donde la población femenina supera a la masculina. Haciendo también referencia a estos datos, encontramos que la tasa de dependencia (menores de 15 años y mayores de 65), está incidiendo a nivel social en la calidad de vida no solo de las personas dependientes sino de las personas que cuidan, generalmente mujeres, este detalle tiene una importante lectura desde el punto de vista de género y de la trasmisión de responsabilidades que recaen en las mujeres y que están directamente relacionadas con la división sexual del trabajo y las oportunidades de promoción de las mujeres. Por este motivo he creído conveniente puntualizarlo 


\section{2.- Nivel de estudios}

\section{Población por nivel de estudios y sexo. Dato comarcal}

En cuanto a la población por nivel de estudios y sexo, encontramos que en la mayoría de los casos el número de hombres supera al de mujeres excepto en la obtención de diplomaturas en las que superan a los hombres con 469 y 372 respectivamente. El dato más sorprendente es que el analfabetismo en mujeres supone el doble que los hombres (887 y 435), sin embargo son los hombres los que más aparecen sin estudios aunque el dato no es significativo.. Si es cierto que los datos son del año 2001 y no están actualizados, habría que tener en cuenta este punto ya que es esperable que hayan podido variar, sobre todo si tenemos en cuenta que la existencia de escuelas de para personas adultas ha podido contribuir a la bajada de la tasa de analfabetismo y de sin estudios.

\begin{tabular}{|c|c|c|}
\hline & MUJERES & HOMBRES \\
\hline Analfabetas & 887 & 435 \\
\hline Sin estudios & 2.432 & 2.486 \\
\hline Primer Grado & 2.384 & 2.858 \\
\hline $\begin{array}{l}\text { ESO, EGB, Bachillerato } \\
\text { Elemental }\end{array}$ & 2.634 & 2.687 \\
\hline Bachillerato Superior & 724 & 767 \\
\hline FP Grado Medio & 164 & 166 \\
\hline M FP Grado Superior & 196 & 227 \\
\hline M Diplomatura & 469 & 372 \\
\hline M Licenciatura & 196 & 209 \\
\hline M Doctorado & 6 & 4 \\
\hline
\end{tabular}

\section{Centros Educativos}

Respecto a la existencia de centros educativos, todos los municipios poseen Centros Públicos de Educación Infantil y Primaria y de Educación Secundaria Obligatoria excepto Carratraca destacando Campillos y Sierra de Yeguas con dos cada uno. Ambos pueblos junto a Cañete la Real poseen Educación Especial. Los centros concertados de Educación están presentes en Campillos que cuenta uno de Enseñanza General Básica y dos de Enseñanza Secundaria Obligatoria y Teba con uno de Educación General Básica ${ }^{55}$. Campillos vuelve a destacarse por poseer centros en los

\footnotetext{
${ }^{55}$ Fuente: Instituto de Estadística de Andalucía, años 2005 y 2011
} 
que se puede cursar el Bachillerato, Formación de Grado Medio y Educación Secundaria para personas adultas.

Por tanto podemos concluir que las posibilidades de formación en la comarca son bastantes altas atendiendo al número de población ya que las oportunidades de formación alcanzan hasta el bachillerato y a la Formación Profesional de grado medio.

\section{3.- Mercado de trabajo}

La principal fuente de riqueza y empleo, se centra en la ganadería avícola y porcina, junto con los cultivos de cereales y olivar. Por otro lado, encontramos en el sector servicios un segundo pilar de la economía; concretándose en pequeños negocios de hostelería y comercio escasamente profesionalizados y de gestión familiar por lo que la oferta de empleo en la comarca es escasa.

Es en el sector servicios donde las mujeres encuentran amplia representación, además de en las empresas agroalimentarias de manufactura y en la atención a personas dependientes.

\section{Población ocupada por sexo}

La población ocupada de la comarca está representada por un 72,8 de hombres, frente a un $27,2 \%$ de mujeres. Se manifiesta una clara brecha de género en la empleabilidad comarcal con una diferencia entre hombres y mujeres. Este indicador se haya con el conjunto de personas de 16 o más años, residentes en viviendas familiares que durante la semana de referencia trabajaron al menos 1 hora o estaban temporalmente ausentes del trabajo por motivos varios (bajas, etc.).

\begin{tabular}{lr||r||r}
\multicolumn{1}{l}{ MUJERES } & \multicolumn{1}{c|}{ HOMBRES } & TOTAL \\
\hline \hline ALMARGEN & 259 & 468 & 728 \\
\hline ARDALES & 266 & 481 & 748 \\
\hline CAMPILLOS & 937 & 1.713 & 2.650 \\
\hline CAÑETE LA REAL & 227 & 284 & 511 \\
\hline CARRATRACA & 68 & 110 & 178 \\
\hline CUEVAS DEL BECERRO & 159 & 222 & 381 \\
\hline SIERRA DE YEGUAS & 341 & 646 & 987 \\
\hline TEBA & 302 & 550 & 852 \\
\hline \hline
\end{tabular}

Fuente IEA Instituto de Estadística de Andalucía, SIMA, datos 2011 y elaboración propia 


\section{Trabajadoras y trabajadores eventuales agrarios subsidiarios por sexo}

Los datos referidos a las personas trabajadoras eventuales del Régimen Especial Agrario de la Seguridad Social que al término del mes están percibiendo el subsidio agrario, regulado por Real Decreto 5/1997. Como puede observarse en la tabla, nos encontramos en una comarca con un nivel muy alto de dependencia de su población al cobro del subsidio agrario, sobre todo en las mujeres

\begin{tabular}{lr||c||c|}
\multicolumn{2}{l|}{ MUJERES } & \multicolumn{1}{c|}{ HOMBRES } & TOTAL \\
\hline \hline ALMARGEN & 62 & 29 & 91 \\
\hline ARDALES & 119 & 28 & 147 \\
\hline CAMPILLOS & 217 & 51 & 268 \\
\hline CANETE LA REAL & 94 & 51 & 145 \\
\hline CARRATRACA & 19 & 6 & 25 \\
\hline CUEVAS DEL BECERRO & 32 & 82 & 114 \\
\hline SIERRA DE YEGUAS & 170 & 52 & 222 \\
\hline TEBA & 261 & 115 & 376 \\
\hline \hline
\end{tabular}

Fuente IEA Instituto de Estadística de Andalucía, SIMA, datos 2011 y elaboración propia

\section{Contratos registrados}

En cuanto a los contratos registrados observamos cómo el número de hombres casi duplica al de mujeres. Destaca Campillos como el único municipio en el que los contratos de mujeres superan al de hombres y Sierra de Yeguas y Teba con los que más mujeres contratadas cuentan respecto al resto de pueblos.

\begin{tabular}{lr||r||c|}
\multicolumn{1}{l||}{ MUJERES } & \multicolumn{1}{c|}{ HOMBRES } & TOTAL \\
\hline \hline ALMARGEN & 459 & 1.085 & 1.544 \\
\hline ARDALES & 587 & 650 & 1.237 \\
\hline CAMPILLOS & 524 & 485 & 1.009 \\
\hline CAÑETE LA REAL & 83 & 122 & 205 \\
\hline CARRATRACA & 125 & 200 & 325 \\
\hline CUEVAS DEL BECERRO & 388 & 568 & 956 \\
\hline SIERRA DE YEGUAS & 1.410 & 2.649 & 4.059 \\
\hline TEBA & 846 & 1.657 & 2.503 \\
\hline \hline
\end{tabular}

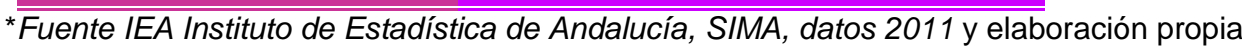




\section{Capítulo 2.- Evolución de la Comarca y Antecedentes desde el punto de vista de la Igualdad de Género ${ }^{56}$}

El territorio que nos ocupa se ha visto favorecida por una serie de transformaciones de gran calado social. Hay que recordar que el punto de partida, hace treinta años, la comarca padecía un mal endémico de la sociedad agraria andaluza: la desigualdad de oportunidades sociales entre las distintas capas ciudadanas que, primero por las condiciones económicas de la posguerra y después, por culpa del desarrollo al margen de los pueblos, había fomentado en los paisajes agrícolas una grave tasa de desempleo.

La Democracia incluyó entre sus objetivos rurales el concepto de políticas sociales, creando prestaciones como el Plan de Empleo Rural que supuso, inicialmente, la paulatina adecuación del trabajo agrario en tareas urbanas, lo que posibilitó, en el caso de la Comarca del Guadalteba, las primeras oportunidades de modernización de los equipamientos y las pequeñas infraestructuras locales. Además, los planes de especialización a partir de cursos realizados por el Ministerio de Trabajo a través de los cursos de Promoción Profesional Obrera (PPO), introdujeron en el mundo laboral no primario a la juventud de la Comarca del Guadalteba. En la actualidad, las soluciones aportadas por las entidades y la propia modernización económica y social de nuestros pueblos, ha rebajado la tasa de desempleo y ha promovido políticas de igualdad de oportunidades

Es a partir del año 1995 cuando se inicia formalmente la puesta en marcha de acciones encaminadas a la implantación del principio de igualdad de oportunidades entre hombres y mujeres en el comarca. Es entonces cuando las instituciones con competencias en el ámbito geográfico del Guadalteba se comprometen a la adopción en un esfuerzo conjunto para trabajar por el desarrollo económico desde una perspectiva social basada en el enfoque de género. Un año más tarde se crea el Consejo Comarcal de la Mujer. Hasta dicha fecha, si bien existían vestigios de lo que posteriormente ha dado lugar a la implantación de las denominadas políticas de Igualdad y el mainstreaming de género; sin embargo aquellos "cimientos" eran hechos puntuales o

\footnotetext{
${ }^{56}$ Extracto de la Nueva Estrategia Rural para Andalucía. Anexo Género del estudio de la comarca Guadalteba
} 
aislados y carentes de la propia filosofía de género:

a) Existencia de un incipiente tejido asociativo femenino cuyos objetivos no estaban propiamente relacionados con reivindicaciones de igualdad entre hombres y mujeres, sino que estaban orientados a la realización de actividades de encuentro y entretenimiento encauzadas por los Centros de Educación de Personas Adultas.

b) La mayoría de los municipios tenían en sus equipos de gobierno Concejalías de Mujer, aunque con recursos deficitarios, o en el peor de los casos, sin partida presupuestaria alguna.

c) El modelo social imperante en nuestros pueblos, era esencialmente patriarcal, con carencia absoluta de conciencia de género y por tanto impermeabilizado frente a las recomendaciones propuestas por los organismos de igualdad más próximos (Instituto Andaluz de la Mujer y Servicio Provincial de la Mujer de la Diputación Provincial).

Es este panorama el antecedente inmediato y previo al trabajo de género que se viene realizando desde 1995, se abre una línea de trabajo multidisciplinar y participativa desde la perspectiva de género a partir de la conjunción de cuatro factores determinantes:

1.- La constitución del Grupo de Desarrollo Rural del (GDR) Guadalteba en 1995.

2.- La puesta en marcha de la iniciativa de la Consejería de Agricultura y Pesca de la Junta de Andalucía para la incorporación de la perspectiva de género en las actuaciones de Desarrollo Rural (con convocatorias periódicas desde 1999 a 2007).

3.- La creación del Centro Comarcal de Información de la Mujer (CIM), mediante convenio con el Instituto Andaluz de la Mujer en 1995.

4.- La creación del Consejo Comarcal de la Mujer en 1996 como órgano consultivo y para la coordinación de las políticas municipales para la Mujer.

A su vez, el Plan de Igualdad de Guadalteba recoge también en su redacción la participación social y política de las mujeres: 'El logro de una sociedad más igualitaria en nuestra comarca, pasa ineludiblemente por apoyar, incrementar y promocionar la participación social y política de la mujer. Ello sería la línea básica a seguir para acabar con el aislamiento social y con el mutismo al que tradicionalmente se han visto 
sometidas las mujeres de Guadalteba, al igual que todas las mujeres de las zonas rurales'. Entre sus objetivos respecto a la participación están el fomento de la participación de las mujeres en el ámbito político y social y apoyar el relevo generacional en las Asociaciones de mujeres ${ }^{57}$.

${ }^{57}$ Extraído del Plan de Igualdad del Consorcio Guadalteba. Archivo del Consorcio Guadalteba 


\section{IV.- PARTICIPACIÓN Y LIDERAZGO DE LAS MUJERES EN LA COMARCA DEL GUADALTEBA: UN COMPLEJO PROCESO DE CAMBIO Y RESISTENCIA}

A continuación expondré el desarrollo específico de mi investigación basándome en los tres ejes que la vertebran: la participación y el liderazgo de mujeres en la política municipal, participación y liderazgo en las asociaciones de mujeres y la acción institucional del Consejo Comarcal de la Mujer teniendo en cuenta los criterios metodológicos que he mencionado en el apartado correspondiente.

Detallo que la media de años de participación en la política municipal es de 6 , mientras que la asociativa es de 10. Recordemos que la participación comienza en las asociaciones y que incluso continúa la actividad en aquellas mujeres que abandonan la política municipal. De alguna manera, la mayoría siguen vinculadas a procesos participativos desde las asociaciones no solo de mujeres.

\section{Capítulo 1.- Mujeres en las asociaciones. La participación pública en la comarca del Guadalteba.}

\section{Las Asociaciones de Mujeres, motor de dinamización para la participación}

Para este apartado me centraré en el trabajo de las asociaciones de mujeres por ser las que directamente trabajan en la promoción de la igualdad de género y en la lucha por vindicar el protagonismo de las mujeres en los espacios públicos. Analizaré las motivaciones, las iniciativas que toman, los mecanismos de funcionamiento, cómo se relacionan entre ellas y con la comunidad, cómo ejercen su liderazgo y cómo lo perciben.

Las asociaciones de mujeres han constituido un espacio único desde donde se han articulado la mayoría de las acciones y estrategias de presión vindicativa para la adquisición de derechos y para cambiar la vida de las mujeres de los pueblos. Esta vida se ha caracterizado por el aislamiento que supone vivir en un entorno rural marcado en mayor medida por los roles que impone el sistema patriarcal. Desde sus inicios, muy difíciles como manifiestan las más veteranas, los objetivos han ido cambiando conforme 
se han ido consiguiendo parcelas de igualdad. Si es cierto, que al contrario de las mujeres en la política municipal, al no invadir un terreno propio de hombres, desde fuera se ha llevado con más normalidad su existencia por ser catalogadas como 'cosas de mujeres'

'Cuando pudimos tener el local fue maravilloso $; i$. Allí podíamos fumar y tomarnos nuestro cafelito sin que nadie nos dijera nada. ${ }^{58}$

(Presidenta de Asociación de Mujeres, 70 años, sin estudios)

'Se ha avanzado mucho, lo de estar aqui tomándome un café contigo antes era imposible.

El panorama asociativo en la comarca es bastante extenso y las mujeres están representadas en mayor número en la mayoría de las asociaciones existentes como son las Asociaciones culturales, Asociaciones de Madres y Padres (AMPAS), Coordinadora de Asociaciones de personas con discapacidad del Guadalteba (COAGU), parroquiales, etc. donde no siendo específicamente de mujeres destacan por una gran mayoría de asociadas respecto a los hombres. No es el caso de las asociaciones de cofradías o las deportivas en las que la presencia y el protagonismo de las mujeres es muy reducido. Actualmente existen doce asociaciones de mujeres en la comarca:

Asociación de mujeres Albahaca de Almargen

Asociación de mujeres Futuro de Ardales

Asociación de mujeres Arco Iris de Campillos

Asociación de mujeres Selene de Campillos

Asociación de mujeres Albacara de Cañete

Asociación de mujeres Yerma de Cañete

Asociación Las Boleras de Carratraca ${ }^{59}$

Asociación de mujeres La Mojea de Cuevas del Becerro

Asociación de mujeres Luna Creciente Sierra de Yeguas

Asociación de mujeres Escalera de Color de Sierra de Yeguas

\footnotetext{
${ }^{58}$ Testimonio de una Presidenta, 70 años de edad

${ }^{59}$ Destacar que esta es asociación es de nueva creación
} 
Asociación de mujeres Siete de septiembre de Serrato

Asociación de mujeres Eugenia de Montijo de Teba

Asociación de Mujeres Empresarias y Emprendedoras del Guadalteba

\section{(ADMEYé)}

En total el número de asociadas asciende a $800^{60}$, por lo que el espectro que ocupan es bastante amplio. Todas estas asociaciones están federadas, excepto la de Carratraca de reciente creación, dentro de la Federación de Asociaciones de Mujeres de Peñarrubia que cada año celebra su existencia con un Encuentro Comarcal de Asociaciones de Mujeres que se enmarca cada año en una temática que decide el Consejo Comarcal de la Mujer y que cuenta ya con trece ediciones. Es la Federación la que marca las pautas junto al CCM de las acciones anuales comarcales que se llevan a cabo en la comarca en materia de igualdad. Además de estar constituidas en Federación de asociaciones, también pertenecen al Consejo Provincial de la mujer y al Consejo Andaluz de Participación de las Mujeres.

En la actualidad algunas de ellas tienen baja actividad, como es el caso de Yerma de Cañete la Real y Luna Creciente de Sierra de Yeguas. Según las entrevistadas existen muchos problemas en las asociaciones de mujeres para hacer partícipes a las mujeres de la comarca para que se impliquen en la actividad asociativa que llevan a cabo. En muchas ocasiones han tomado iniciativas para motivarlas hacia la participación pero la respuesta no ha sido significativa. Entre las causas que manifiestan al respecto están los recortes en igualdad, la falta de relevo generacional y la no renovación de los cargos directivos. La visión que se tiene de la juventud en general es de falta de interés hacia casi todo lo que provenga de las asociaciones de mujeres y no existe una motivación por llevar las cuestiones de igualdad de género a debate. Nos encontramos por tanto con un perfil de asociaciones en las que la media de edad aproximada es de 45 años, sin relevo generacional, con poca colaboración entre las socias para llevar la Junta Directiva y con la desmotivación de las jóvenes no asociadas por los temas de igualdad.

\footnotetext{
${ }^{60} \mathrm{El}$ dato es aproximado puesto que no hay una actualización de los libros de asociaciones y por lo tanto no existe una actualización de las bajas y altas en las asociaciones.
} 
'Los recortes están haciendo que nos estanquemos y que vayamos atrás, con lo que hemos luchao las mujeres mayores desde la lucha por la ley del divorcio que también defendimos desde la asociación'

(Presidenta de Asociación de Mujeres, 70 años, sin estudios)

'Estamos estancadas, los cargos directivos nadie los quiere y es importantísimo que las mujeres más jóvenes se impliquen en las asociaciones. La inquietud que teníamos antes no se la veo ahora a la juventud, ellas piensan que la igualdad está ya conseguida'

(Presidenta de Asociación de Mujeres, 58 años, Graduado Escolar)

'Una amiga tuvo que quedarse viuda para poder hacer las cosas que quería y yo le dije, eso lo deberías decir en un sitio donde haya hombres, qué pena me daba a mí que una mujer tuviese que esperar a que se muriese tu compañero de toda la vida para empezar a vivir...eso es muy triste...pero las mujeres siempre tiramos para adelante, siempre, incluso de mayores aprendemos y emprendemos. Las mujeres jóvenes no se dan cuenta de las trabas que hemos tenido'

(Exconcejala de Medioambiente y Cultura, 52 años, sin estudios)

'A mí me gusta ir a la asociación pero cuando hay algo que me interesa, si no, no voy. Las mujeres de allí siempre se están quejando de que no entramos en la junta directiva las chicas más jóvenes, pero es que yo no puedo ni me motiva tampoco y la gente que conozco está estudiando fuera'

(Socia de 33 años de edad, Graduado Escolar)

Los talleres de empoderamiento, liderazgo y autoestima del Instituto Andaluz de la Mujer y del Área de Políticas de Igualdad de la Diputación de Málaga junto a otro tipo de talleres destinados a las asociaciones, han contribuido mucho al cambio de mentalidad de las mujeres rurales en los últimos años y a la relación que se establece entre ellas. Aunque todavía hay mucho que trabajar en este sentido, existe una mayor concienciación de que la sororidad debe de ser la forma en la que se relacionen y están llevando a cabo iniciativas en este sentido. Una de ellas fue el Encuentro de Sororidad del año 2011 para reconocer a las concejalas de igualdad.

En cuanto a la relación con los ayuntamientos en general es buena, incluso en muchas de ellas la implicación es muy estrecha. Reconocen la necesidad de ser autónomas pero ven la necesidad de hacer visibles también a las asociaciones como tales. El asociacionismo femenino vertebra la agenda de igualdad en la mayoría de los pueblos y actúa incentivando la participación de las mujeres en la política local. No 
olvidemos que muchas de las que entran en política ya estaban presentes antes en el tejido asociativo de mujeres entre otros.

'Siempre que necesito contar con ellas las tengo, y creo que la ayuda es mutua. Para mí es muy importante tener una buena relación con todas las asociaciones y con la de mujeres más ya que tenemos los mismos intereses'

(Concejala de Igualdad, 43 años, diplomada)

Su proyección hacia el exterior la hacen a través de acciones reivindicativas para los días señalados de la agenda feminista como son el Día Internacional de la Mujer, el Día internacional de la violencia contra las mujeres, el Día internacional de la salud de las mujeres, el Día internacional de la mujer rural, etc. siguiendo la línea marcada por el Instituto Andaluz de la Mujer a través del Centro de Información a la Mujer del Consorcio Guadalteba. Realizan manifestaciones y campañas institucionales en los días señalados anteriormente, talleres abiertos a todas las mujeres del municipio para captar socias, colaboraciones con otras entidades como son las AMPAS, actos benéficos, etc.

A parte de la programación anual conjunta con el CCM, tienen sus propias programaciones que van desde la realización de talleres de variada temática hasta las actividades culturales y de ocio y tiempo libre, si bien es cierto que muchas de ellas no tienen que ver con la igualdad e incluso reproducen talleres tradicionales como son los de costura y manualidades. Destaca la Semana de la Mujer en conmemoración del 8 de marzo en el que se alternan en la mayoría de los pueblos talleres feministas y actividades de ocio y con los que se hacen visibles y partícipes a toda la población. A parte, cada una de ellas tiene su propia programación que incide en lo local. Los mecanismos de participación los hacen a partir de las acciones conjuntas y colaborativas, he aquí una motivación que les lleva a participar colectivamente y donde las referencias de otras mujeres se consideran importantes.

Sin duda son muchas las iniciativas que se han apoyado desde las asociaciones y que se están relacionadas con el avance de las mujeres rurales. Sin embargo podemos concluir que existen dos características importantes en ellas y que tienen que ver con las quejas que ellas mismas manifiestan. Una de ellas es a lo que al relevo generacional se refiere, nos encontramos con asociaciones de mujeres en la que la mayoría son mujeres mayores de 45 años, y por otro lado son asociaciones que por la propia dinámica se han 
vuelto muy dependientes de la agenda política feminista y del apoyo financiero de las instituciones en materia de Igualdad de Género.

\section{Capítulo 2.- Mujeres, Participación política y Liderazgo en la}

\section{Comarca del Guadalteba}

La participación política en las mujeres de la Comarca de Guadalteba se ha caracterizado tradicionalmente por una baja representación en los órganos de decisión. Esta situación está cambiando como se demostrará a continuación tras el análisis de las listas electorales en las cuatro últimas legislaturas.

Me he centrado en las elecciones municipales a raíz de la creación del Consejo Comarcal de la Mujer en 1996 y he partido de las elecciones de 1995 por ser las más próximas y anteriores y del análisis de las entrevistas y de los datos cuantitativos recabados en cuanto a la presencia tanto en las listas electorales como en las concejalías y alcaldías elegidas. He tenido en cuenta principalmente los siguientes factores:

- Presentación a listas de partidos políticos

- Puestos asignados en las listas de los partidos políticos

- Número de Concejalas elegidas

- Número de Alcaldesas

- Motivos que las llevan a presentarse

- Motivos que las llevan a abandonar la política

- Acciones para ejercer su liderazgo, iniciativas que llevan a cabo y cómo lo hacen

Los partidos que he tenido en cuenta son todos los que se presentaron a las elecciones municipales de los ocho pueblos que componen la comarca desde 1995 a 2011 y son los siguientes:

Alternativa Local por Sierra de Yeguas (AL)

Asociación del Pueblo Serrano (APS)

$\checkmark$ Espacio Plural Andaluz (EP-AND)

$\checkmark$ Falange Auténtica (FA)

$\checkmark$ Agrupación de Electores Grupo Social Independiente (GSI) 
$\checkmark$ Independientes por Almargen (I POR AL)

$\checkmark$ Izquierda Unida Los Verdes-Convocatoria por Andalucía (IULV-CA)

$\checkmark$ Partido Andalucista (PA)

$\checkmark$ Partido Popular (PP)

$\checkmark$ Partido Socialista Obrero Español (PSOE)

Se han realizado 11 entrevistas a mujeres de todos los partidos anteriores excepto de los que en las últimas legislaturas no se han presentado a las elecciones, estos son Falange auténtica (Ardales), Asociación del Pueblo Serrano (Sierra de Yeguas) y Agrupación de Electores Grupo Social Independiente (Cañete la Real). Algunas de las entrevistadas no están en la esfera política actual de los ayuntamientos, sin embargo se han incluido en el estudio por el interés de sus testimonios tanto por las motivaciones que las llevaron a incorporarse como los motivos del abandono.

Paso a analizar los datos estadísticos seguidos de las entrevistas en ese orden y ofreceré los datos de las mujeres representadas en las listas electorales desde las elecciones municipales de 1995.

\section{1.- Representación de las Mujeres en las listas electorales y en la política municipal}

A continuación analizamos la representación de las mujeres en las listas electorales a través de los datos recogidos que pueden consultarse en el Anexo 1 (tablas $1,2$ y 3$)^{61}$.

Por partidos políticos y trayectoria de encabezar las listas destaca IULV-CA y PSOE siendo los que más veces llevan como cabeza de lista a una mujer. En concreto en la legislatura de 2011, tres de los pueblos de la comarca: Ardales, Cañete la Real y Teba en el caso del PSOE y Cañete, Cuevas y Sierra de Yeguas en 2007 con IULV-CA. El PP con dos, Carratraca y Cuevas del Becerro en 2011. Entre los partidos minoritarios solo EP-AND lleva en 2011 a una mujer como cabeza de lista en Teba.

Todos los partidos mayoritarios tienen a mujeres en sus listas, es importante destacar el aumento de mujeres que la encabezan, como podernos ver en los datos de la

\footnotetext{
${ }^{61}$ Los datos anteriores no están digitalizados y no se han podido conseguir para el presente estudio.
} 
representación en la lisas, anexo 1, no es el caso de los partidos minoritarios donde la presencia de las mujeres es muy baja.

Por municipio es Carratraca quien se destaca por ser el pueblo en el que más veces ha encabezado las listas una mujer. En concreto en cuatro ocasiones, tres de ellas como representantes del PP y una con IULV-CA. Les sigue con tres Cuevas del Becerro (PP en 2011 e IULV-CA en 2003 y 2007) y Teba (PSOE en 2003, 2007 y 2011). Es importante decir que en el caso de Cuevas del Becerro y Teba las que encabezaban las listas repitieron candidatura; esto es, son las mismas mujeres lo cual nos indica que poseen un liderazgo bastante consolidado. No ocurre lo mismo en otros municipios como Sierra de Yeguas en los que las mujeres no solo no volvieron a estar en cabeza de lista, sino que desaparecieron de la escena política (las razones de ello se puntualiza en el apartado de motivaciones y razones del abandono de la política). Es el año 2007 donde más cabezas de listas representadas por mujeres observamos, en concreto 6 , Cañete (PP e IU), Carratraca (PP), Teba (PSOE) y Sierra de Yeguas (IU y PSOE) ${ }^{62}$

El punto fuerte es que en la actualidad existe el mismo número de alcaldesas que de alcaldes, por lo que la representatividad del máximo poder local existe paridad. En el caso concreto del municipio de Teba, la misma mujer es reelegida como alcaldesa en dos legislatura (2003 y 2011) como veremos más adelante.

\section{Mujeres como Concejalas}

Las elecciones municipales de 1999 suponen un punto de inflexión en las concejalas elegidas, los datos muestran un cambio importante en el que podemos observar la progresión. Destacan los municipios de Sierra de Yeguas, Campillos y Cañete la Real con el 50\%, 42,8\% y 45,4\% de concejalas elegidas respectivamente en esta legislatura. Por lo que podemos concluir que las medidas legales hacia la paridad contribuyen de manera positiva en la participación política de las mujeres, sobre todo en el caso de los partidos que empezaron a aplicarla antes de la obligación de la ley de 2007, PSOE e Izquierda Unida.

Los pueblos que han aumentado el número de mujeres concejalas a lo largo de las cuatro legislaturas estudiadas son Almargen, Carratraca y Cuevas del Becerro, se

\footnotetext{
62 Este año fue la entrada de la Ley 3/2007 explicada anteriormente, lo cual nos lleva a pensar su influencia en este aumento
} 
han mantenido Cañete la Real y Teba y destacan Ardales, Campillos y Sierra de Yeguas con una disminución en las elecciones de 2007 respecto a las de 1999 (las causas de esta disminución suponen un reto para una posterior investigación) lo cual nos puede llevar a pensar en cierto retroceso; estas características forman parte de todos los cambios sociales en los que las conquistas no son globales sino que están inmersas en una dinámica de fluctuaciones que dependen también de la propia dinámica de la política del propio municipio.

Concejalas legislaturas 1995-2011

\begin{tabular}{|c|c|c|c|c|c|}
\hline & 1995-1999 & $1999-2003$ & 2003-2007 & 2007-2011 & 2011-2014 \\
\hline ALMARGEN & $27,2 \%$ & $30 \%$ & $50 \%$ & $27,2 \%$ & $18,1 \%$ \\
\hline ARDALES & $36,3 \%$ & $38,4 \%$ & $36,3 \%$ & $27,2 \%$ & $45,4 \%$ \\
\hline CAMPILLOS & $28,5 \%$ & $42,8 \%$ & $30 \%$ & $30,7 \%$ & $30,7 \%$ \\
\hline CAÑETE LA REAL & $27,2 \%$ & $45,4 \%$ & $60 \%$ & $54,5 \%$ & $33,3 \%$ \\
\hline CARRATRACA & $0 \%$ & $14,2 \%$ & $33,3 \%$ & $42,8 \%$ & $57,1 \%$ \\
\hline $\begin{array}{l}\text { CUEVAS DEL } \\
\text { BECERRO }\end{array}$ & $20 \%$ & $33,3 \%$ & $33,3 \%$ & $40 \%$ & $44,4 \%$ \\
\hline TEBA & $18,1 \%$ & $30 \%$ & $33,3 \%$ & $36,3 \%$ & $36,6 \%$ \\
\hline $\begin{array}{l}\text { SIERRA DE } \\
\text { YEGUAS }\end{array}$ & $0 \%$ & $50 \%$ & $50 \%$ & $27,2 \%$ & $27,2 \%$ \\
\hline
\end{tabular}

\section{Mujeres como Alcaldesas}

Actualmente en la comarca existen 4 alcaldesas gobernando, por lo que podemos afirmar que en cuanto al liderazgo en la jerarquía política municipal, contamos con el mismo número de alcaldesas que de alcaldes. Dato muy significativo y bastante esperanzador en cuanto a la presencia de mujeres en las posiciones de mando. Tres de ellas pertenecen al PSOE y una al PP. El partido que más veces ha sido gobernado por una mujer ha sido el PSOE con 4, seguido del PP e IULV-CA con 2. Destaco la reelección de la alcaldesa de Teba, Isabel Garnica Báez del PSOE, que ha sido cabeza de lista en 3 ocasiones y elegida en las legislaturas de 2003-2007 y 2011-2014, por lo tanto nos encontramos con una claro ejemplo de afianzamiento de liderazgo. 
Las otras alcaldesas a las que quiero hacer mención son Isabel Teresa Rosado Esquina de Cuevas el Becerro representando a Izquierda Unida en la legislatura 20032007, y Marian Fernández Espejo de Carratraca representando al Partido Popular en la presente legislatura (2011-2014). Un detalle importante es que El 80\% de las mujeres que se presentaban a la reelección son las mismas mujeres, lo que nos lleva a pensar que en cuanto al afianzamiento del liderazgo en la comarca el número no ha aumentado en los últimos años ya que es ostentado casi siempre por las mismas mujeres. Incluso encontramos mujeres entrevistadas que fueron cabezas de lista de sus partidos y que en el presente ya no están en la esfera política.

Alcaldesas legislaturas 1995-2011

\begin{tabular}{|c|c|c|c|c|c|}
\hline & 1995-1999 & $1999-2003$ & 2003-2007 & $2007-2011$ & 2011-2014 \\
\hline ALMARGEN & & & & & $\mathbf{1} *(\mathrm{PSOE})$ \\
\hline ARDALES & & & & & \\
\hline CAMPILLOS & & & & & \\
\hline CAÑETE LA REAL & & & & & 1 (PSOE) \\
\hline CARRATRACA & & & & & $1(\mathrm{PP})$ \\
\hline $\begin{array}{l}\text { CUEVAS DEL } \\
\text { BECERRO }\end{array}$ & & & 1 (IULV-CA) & & \\
\hline $\begin{array}{l}\text { SIERRA DE } \\
\text { YEGUAS }\end{array}$ & & & & & \\
\hline TEBA & & & 1 (PSOE) & & 1 (PSOE) \\
\hline
\end{tabular}

Se observa por tanto que aunque las mujeres están menos representadas que los hombres en las listas y ocupan puestos más secundarios en el conjunto y, aunque las cifras varían dependiendo de los pueblos y las fechas como se ha comentado anteriormente, el aumento en el periodo de tiempo estudiado nos hace dar cuenta que ha habido un aumento considerable en su representación ya que existen más mujeres en listas que antes, más mujeres concejalas y más mujeres alcaldesas. 
Podemos entonces afirmar que en los últimos años el afianzamiento de liderazgo en la comarca ha aumentado considerablemente, otra cuestión interesante sería analizar cómo ejercen ese liderazgo y cómo llevan a la práctica su grado de autoridad, si estas mujeres líderes están constituyendo y/o potenciando el que otras mujeres puedan coger el relevo del liderazgo, sobre todo en las más jóvenes. Se abre un campo muy interesante para poder continuar con la investigación. 


\section{2.- Género y Empoderamiento de las Mujeres en la vida política}

Como se ha comentado antes, en este capítulos es de interés observar el grado de autonomía que poseen las mujeres, hasta qué punto las mujeres estudiadas rompen con los papeles tradicionales de género, cómo conciben la igualdad y hasta qué punto se relacionan con el feminismo.

Las primeras mujeres que entraron en política de los municipios estudiados tuvieron que enfrentarse a obstáculos que en el presente afortunadamente no se dan al menos en esa medida. Nos encontramos con las primeras concejalas que tuvieron que luchar muy duro por hacerse un sitio en sus partidos y en la política local. Fueron juzgadas no solo por sus compañeros de partido sino por el pueblo en general, se sentían mujeres escaparate y muchas de ellas estaban solas en los partidos. Estas mujeres han sido las pioneras y las que han ido abriendo camino a las siguientes. Afortunadamente la aceptación de la presencia de mujeres está tomando el sentido de valoración y en estos momentos, en los ocho pueblos de la comarca, está más o menos normalizada y la conciencia de género en la ciudadanía ha aumentado conforme a la participación y el aumento de su presencia en las listas en los partidos, aunque sigue habiendo factores propios del patriarcado que llevan a las mujeres el 'pensarse más de una vez si entrar o no a la escena política'. No es así en las asociaciones, donde esta presencia está más normalizada al ser un espacio propio de mujeres.

En cuanto a sus aspiraciones de escalar en política, la mayoría de las entrevistadas no tienen grandes ambiciones al respecto; en principio solo el interés local está en sus planes. Algunas de ellas, sobre todo las más jóvenes no descartan seguir escalando en la esfera política pero a largo plazo:

'Por ahora no me planteo seguir escalando, estoy en el presente y el presente es poder ayudar a mi pueblo, aunque no descarto en un futuro si se dan las circunstancias seguir a otros niveles, pero eso es a largo plazo y sin habérmelo planteado seriamente'

(Concejala de Economía, 27 años, licenciada) 
Las razones del abandono de la política en todas las entrevistadas que lo hicieron fueron la presión desde el propio partido, sus opiniones no eran tenidas en cuenta y eran menospreciadas e instrumentalizadas además de ser ignoradas en sus quejas hacia instancias superiores.

'Salí tan quemada a todos los niveles que creo que no volvería, no lo tengo claro. Cuando me quejé de mi situación al partido provincial ni me hicieron caso, me defraudaron mucho...me encontré sola. Tendrían que darse unas circunstancias muy distintas para volver...'

(Ex concejala, 52 años, diplomada)

Ven la necesidad de tener un estilo propio de hacer política; 'un estilo femenino' y el apoyo común entre mujeres basado en la sororidad:

'Los hombres tienen otro estilo de hacer politica, son más ego centristas, las mujeres miramos más por el bien común, compartimos más y queremos repartir, como cuando tienes un plato de comida y quieres para todo el mundo igual, el hombre dice, si, vamos a repartir pero veremos a quien le toca y de qué manera. Nosotras somos más prácticas en la política, aunque muchas veces topamos con mujeres que ejercen la política imitando a los hombres y de manera machista. Las mujeres tenemos que estar en política pero bajo nuestros cánones, sin imitar a los hombres, siendo nosotras mismas ${ }^{, 63}$

(Ex concejala y ex presidenta del CCM, 56 años, sin estudios)

'Las mujeres tenemos que apoyarnos más unas a otras y poner por encima de todo la igualdad a los partidos y las ideologías porque tenemos todas una problemática común que no tienen los hombres pero muchas veces no nos damos cuenta y nos tiramos unas a otras'

(Socia de Asociación de Mujeres, 46 años, Graduado Escolar)

Seguimos observando un importante cambio en poco tiempo, a pesar de las dificultades de los comienzos, las mujeres han estado y siguen ahí, conquistando parcelas de poder. Lo cual está relacionado con factores internos que tienen que ver con el afianzamiento de su liderazgo y con factores externos como son las medidas de paridad dentro de los partidos y las leyes a pesar de que no lo hacen por iniciativa propia la mayoría de las veces. A pesar de esta consolidación, no parece que exista mucha ambición en ellas en cuanto a subir peldaños en la jerarquía política, en este sentido se muestra mucho conformismo y una falta de reconocimiento propio. Por otro lado las que abandonaron la política lo hicieron por factores que tenían que ver con la 
imposición desde los partidos a tomar medidas con las que no estaban de acuerdo, lo cual muestra su convicción del defender lo que creen justo pero por otro lado ese dejar de estar presentes las llevan a desaparecer de la esfera política, lo cual no deja de ser una pérdida. De nuevo nos encontramos con hechos que parecen contradecirse ya que también en cuanto al ejercicio del liderazgo reconocen la necesidad de apropiarse de un estilo 'femenino' porque aún no poseen uno propio.

\subsection{1.- Motivaciones y Razones para acceder a la vida política municipal}

Las preguntas a las que quiero contestar en este apartado son entre otras ¿Qué motiva a las mujeres del Guadalteba su entrada en la política? ¿Qué razones le llevan a hacerlo? En el caso de abandono, ¿por qué lo hicieron? ¿Tienen aspiraciones para seguir escalando en esta esfera? ¿Consideran su presencia en los ayuntamientos importante, y sus acciones?

El 90\% de las entrevistadas han entrado en política no por iniciativa propia, sino porque los partidos las llamaron a formar parte, hombres casi en su totalidad. Algunas de ellas con trayectoria política en la familia de sus padres, las más jóvenes lo han vivido de otra manera, lo han vivido en democracia y muchos de los logros se habían conseguido antes de sus nacimientos, aunque a veces también sufren discriminación por ser jóvenes. Sin embargo las que llevan más tiempo tuvieron la falta de apoyo familiar, sobre todo de sus maridos, y social. Este factor está relacionado con los roles muy marcados que llevan a la gran dificultad de conciliar la vida política con la laboral y familiar y que desde fuera se ve como falta de responsabilidad en muchos casos y desde dentro ellas lo perciban también como un espacio secundario.

La estructura patriarcal tan fuerte con la que tuvieron que lidiar en sus comienzos lo atestiguan declaraciones como las siguientes:

'Donde irá que deja su casa abandonada para meterse en cosas que no debe'.

(Ex concejala de Cultura y Mujer, 49 años, graduado escolar) 
'Los comienzos fueron muy difíciles...empezaron a ponernos en las listas porque los partidos les decian, oye que hay que empezar a meter a mujeres'

(Ex concejala de Mujer y Bienestar Social, 49 años, sin estudios)

'Aquello era un nido de machistas irrespirable. Notabas un ambiente enrarecido en el que te menospreciaban, primero por ser mujer y segundo por el complejo de inferioridad que tenían al tener yo un nivel cultural más alto que ellos'

(Ex concejala de Bienestar Social, 52 años, diplomada)

En las motivaciones de representar a sus pueblos todas las entrevistadas coinciden en que su entrada en la política es para cambiar las cosas y ayudar a sus vecinos y vecinas.

'Mi anhelo y mi deseo es trabajar, lo que se dice trabajar por el pueblo y por las mujeres. Aportar mi granito de arena'

(Alcaldesa, 27 años, licenciada)

El discurso ideológico es secundario a lo que ellas puedan ofrecer desde su trabajo. Se identifican más con las necesidades y potencialidades hacia los problemas comunes que pueden solucionar que a las siglas del partido. Puede ser esa la causa de que muchas de ellas vayan por independiente o no estén afiliadas. Las mueven mecanismos de altruismo y compromiso personal y social y están más concienciadas en los cambios hacia del desarrollo sin tener en cuenta tanto las directrices provinciales, regionales o estatales que imponen los partidos.

'Yo lo tengo muy claro desde el principio, el pueblo está antes que el partido. Si no estoy de acuerdo con algo lo defenderé si es beneficio para el pueblo. La razón por la que estoy aquí es hacer cosas por el pueblo y para la gente del pueblo'

(Representante de lista, 52 años, sin estudios)

Todas apuntan la importancia de la presencia de las mujeres en la política en general y hacen hincapié en la necesidad de visibilizar a las mujeres rurales.

'Yo creo que la vida de una mujer rural es muy distinta a la de una de ciudad desde que se levanta. Las mujeres de los pueblos deberían pasar todas por la política, todas deberían hacer política desde un lado u otro'

(Concejala de Igualdad, 40 años, Formación Profesional Ocupacional) 
Casi todas participaban en asociaciones antes de la política, esto es, en AMPAS, asociaciones culturales, parroquiales, vecinales, etc. y muchas de ellas siguen con la doble militancia, otras la aparcan cuando entran en política y la retoman cuando abandonan. Es por ello que poseen una importante trayectoria en otros ámbitos de participación y por lo tanto habilidades y recursos que las hacen un pilar fundamental de participación.

Concluimos que las mujeres entran en política municipal porque las llaman los partidos en la mayoría de las ocasiones, no porque tomen la decisión. Esto nos lleva a pensar en un grado importante de dependencia que les lleva a no ser absolutas protagonistas de su iniciativa. Encontramos que además las principales motivaciones de las mujeres para entrar en política están basadas en la solidaridad y el altruismo; en la 'ayuda' para llevar a cabo medidas que redunden en beneficio del pueblo. Como hemos podido ver, cuando entran en conflicto los intereses partidistas y los del bien común, la mayoría se postula a favor de lo último (como hemos visto antes, incluso llegan a pagar el precio del abandono o por propia iniciativa o por presión del partido para que abandonen). En estas motivaciones es interesante recalcar qué es lo que hay detrás de esto; ¿las mujeres seguimos estando para 'ayudar'? ¿Se siguen reproduciendo patrones de género incluida la esfera pública? ¿Hasta qué punto desligan las mujeres los terrenos privado y público?

Por otro lado, es importante señalar que el concepto de democracia toma matices diferentes en las mujeres jóvenes, ya que estas han nacido en periodo democrático y tienen otro concepto de ciudadanía. 


\subsection{2.- Cómo viven las mujeres el Liderazgo en la política municipal}

Respecto al cómo ejercen su propio liderazgo o el que pueden llegar a ostentar, resulta muy interesante ver como la mayoría no lo percibe. Casi siempre, excepto las alcaldesas, se apoyan en el líder de partido que en la mayoría de los casos es un hombre. Aceptan el relegarse y no asumen el poder como un aspecto alcanzable, no asumen el protagonismo. Las concejalías que ocupan son en su mayoría Bienestar Social, Mujer, Educación y Festejos, a veces por opción personal y otras por adjudicación. De nuevo encontramos una lectura clara desde el punto de vista del género que tiene que ver con la división sexual del trabajo y la conciliación.

Casi todas estas mujeres participaban en asociaciones antes de la política: AMPAS, asociaciones culturales, parroquiales, etc. y muchas de ellas siguen con la doble militancia. Es por ello que poseen una importante trayectoria en otros ámbitos de participación y por lo tanto habilidades y recursos que las hacen un pilar fundamental de participación, pero no lo ponen en valor.

Las que reivindican su liderazgo son muchas veces castigadas con comentarios machistas muchas veces propiciados por mujeres. Muchas de las entrevistadas me cuentan que las acusaciones viniendo de una mujer son más hirientes, 'porque pensamos que por el hecho de ser mujer vamos a tener su apoyo a priori'. A veces nos olvidamos de que el proceso de socialización para mujeres y hombres ha sido la educación desde el androcentrismo. De nuevo la contradicción de reconocer que necesitan un estilo propio basado en el apoyo mutuo por un lado y por otro la reproducción de los roles tradicionales traducidos en la no aceptación de que las mujeres entren en lo público.

'Una mujer me dijo tú tienes muchos cojones, yo le conteste que esto que yo hacía si lo hiciera un hombre se diría que tío más competente, mas echao palante y más dispuesto, sin embargo la misma actitud en mi me dices que tengo muchos cojones cuando ni siquiera tengo ninguno, tengo jovarios;

(Ex concejala de Bienestar Social y Educación, 52 años, diplomada) 


\subsection{3.- Consideraciones sobre el Feminismo y la Igualdad}

Cuando se les pregunta sobre si se consideran feministas, se ve la diferencia entre las que de alguna manera han recibido formación y las que no. Las primeras lo tienen claro, las segundas no se atreven a etiquetarse pero cuando lo explican lo definen de igual manera. Según Nuria Varela, 'el feminismo es un impertinente pues cuestiona la base del orden social establecido. La misma palabra, feminismo o feminista, incomoda tanto a hombres y mujeres, y una y otra vez se le trata como un tema menor, tanto en la práctica como en la teoría política ${ }^{64,}$ y esto lo he podido comprobar incluso en mujeres que por sus acciones son feministas pero que temen catalogarse como tales.

'Feminista no, yo creo en la igualdad y si eso es ser feminista pues lo seré pero no me gusta la palabra porque te toman por radical'

(Concejala de Economía, 27 años, licenciada)

'Por mucho que me considere feminista, llego a mi casa y me lo faratan ii'

(Ex concejala de Cultura, 54 años, Formación Profesional Ocupacional)

'Para mí el feminismo es que las mujeres tengamos los mismos derechos que los hombres, ni más ni menos' la palabra es muy malinterpretada. Connotaciones negativas las tendrá quien no sepa lo que significa' ojala hubiera más gente feminista, hombres y mujeres'

(Concejala de Educación, 52 años, diplomada)

Las Concejalías de Igualdad rurales son un referente, las mujeres acuden a ella en busca de ayuda y desde éstas junto a las asociaciones de mujeres, se vertebran muchas actividades dirigidas a las mujeres. Eso sí, dependiendo de la conciencia de género que tenga la persona encargada de la concejalía (es importante recalcar que en la comarca todas las Concejalías de Igualdad las llevan mujeres excepto un hombre). Es por ello que las asociaciones de mujeres en la mayoría de los casos son un apoyo primordial para la propia agenda del trabajo con mujeres que llevan a cabo los ayuntamientos, a veces feminista a veces no sobre todo teniendo en cuenta de que no parten de un presupuesto cerrado y muchas veces las acciones dependen de la concesión de subvenciones. Muchas actividades que se ofrecen desde los ayuntamientos están

\footnotetext{
${ }^{64}$ Véase Varela, Nuria (2005). Feminismo para principiantes. Barcelona: Ediciones B.
} 
enmarcadas en las tradicionales y no tienen en cuenta la diversidad. En este sentido queda mucho por andar en cuanto a ofrecer una agenda totalmente feminista y dotar de partida presupuestaria y de apoyo técnico a la concejalía. Destacar la importante labor en estos años que desde el Centro de Información a la Mujer del Consorcio Guadalteba se presta a los ayuntamientos y desde el Programa UNEM ${ }^{65}$ (Unidades de Empleo de Mujeres) ambos del Instituto Andaluz de la Mujer e integrados en el Área de Igualdad del Consorcio

'En muchos ayuntamientos y en la politica en general la igualdad sigue siendo de fachada, hay mucho farol: a la hora de la verdad no es tan importante la igualdad... y siempre se le da más importancia a otras cosas'

(Concejala de Igualdad, 40 años, Formación Profesional Ocupacional)

${ }^{65}$ En la actualidad ya no se presta este servicio 


\section{Capítulo 3.- La Acción Institucional: El Consejo Comarcal de la Mujer de la Comarca del Guadalteba.}

El Consejo Comarcal de la Mujer ${ }^{66}$ nace en 1996 a instancias del Centro de Información de la Mujer (CIM) ${ }^{67}$ del Consorcio Guadalteba. Los antecedentes se encuentran en la existencia de algunas asociaciones de amas de casa amparadas en los centros de educación de personas adultas en los años 80 y en las actuaciones locales aisladas, dirigidas a la erradicación de las discriminaciones a las mujeres promovidas por el Instituto Andaluz de la Mujer. En primera instancia su función fue como órgano consultivo y de coordinación de las políticas de igualdad de género, conforme éstas han ido avanzando la labor consultiva se ha ido enriqueciendo con la de coordinación.

Es un espacio de participación donde las mujeres plantean necesidades, experiencias y propuestas de mejora para promocionar sus derechos, impulsar la participación activa de las mujeres en los espacios de decisión, incentivar la cooperación y el trabajo de red en mujeres rurales y potenciar el logro de avances hacia la igualdad de género en todas las localidades consorciadas. También se evalúan las actuaciones y estrategias comarcales en igualdad de género.

Pretende ser un referente en el conjunto de intereses de las mujeres de la comarca sin distinción alguna, por lo que la participación en él está abierta. Forman dicho Consejo las Áreas de la Mujer e Igualdad de todas las Corporaciones Locales de la Comarca, representantes de cada una de las Asociaciones de Mujeres y Federaciones de mujeres existentes en los municipios que integran el Consorcio, el Centro de Información a la Mujer del Guadalteba, el Área de Políticas de Igualdad de la Diputación Provincial de Málaga y el Instituto Andaluz de la Mujer.

Entre sus funciones más importantes destacan:

a) Informar sobre temas específicos de la mujer, así como proponer alternativas concretas a los problemas que puedan plantearse, para que sean tratados por los entes municipales competentes

\footnotetext{
${ }^{66}$ Se adjunta Anexo de su reglamento

${ }^{67} \mathrm{CIM}$ : Centro de Información a la Mujer del Instituto Andaluz de la Mujer 
b) Elevar a los órganos locales competentes las propuestas y conclusiones elaboradas por dicho órgano en materia de igualdad de oportunidades y perspectiva de género.

La presidenta del Consejo la ostenta la persona que con carácter rotativo desempeña la función de presidencia del Consorcio, cabe señalar que en los años de su existencia se fue delegando esta función y desde el año 2003 es siempre una mujer la que ejerce de presidenta (concejala o alcaldesa de algún pueblo de la comarca). Importante señalar que en los primero años desde su aparición, el CCM tiene presencia masculina, gerente y secretario, algún alcalde, pero desde el 2003 la presencia masculina en este órgano de decisión casi desaparece limitándose solo a alguna presencia puntual de algún alcalde. Consideramos que puede ser debido a la novedad de creación del organismo lo que impulsa a participar, pero que al comprobar que son temáticas exclusivas de promoción de las mujeres se delega en ellas como únicas responsables ${ }^{68}$.

A continuación se ofrece un análisis de las actas del CMM desde el año 1998, no se han podido encontrar las del año 1996. La primera acta de la que parte el análisis es la de octubre de 1996 hasta mayo de 2011. Se han analizado exhaustivamente todas las actas para ver la evolución en las temáticas desde su creación. Las principales temáticas tratadas han sido:

Información sobre convocatorias, subvenciones, proyectos, evaluación de actividades de la semana de la mujer, propuestas comarcales, propuestas de la participación en campañas, análisis de los programas promovidos por el IAM, información sobre otros programas de la consejería de agricultura y pesca (aula itinerante de género, Mujer Rural, etc.), seguimiento de campañas de coeducación, cooperación con la Federación de Asociaciones de Mujeres Peñarrubia, reuniones con otras asociaciones de carácter provincial como Agora o la plataforma de malos tratos de Málaga, revisión del Plan de Igualdad Guadalteba, estudio de mociones de adscripción a campañas vindicativas como la celebración del Día Internacional contra la Violencia hacia las mujeres, creación de comisión comarcal contra los malos tratos (guardia civil, policía local, personal médico), exposición de trabajo realizado por las técnicas del área de igualdad $(\mathrm{CIM} \text { Y UNEM })^{69}$.

\footnotetext{
68 *Fuente: Anexo de Género del NERA Provincial (Málaga)

${ }^{69}$ Atenciones jurídicas, dinamización y empleo
} 
La opinión vertida en las entrevistas lleva a concluir que el CCM constituye un mecanismo que ha contribuido sobremanera a la transformación en la participación de las mujeres de la comarca. El impacto de las propuestas acordadas desde este organismo ha llegado a todos los pueblos mediante estrategias de acción y promoción de la igualdad y los derechos de las mujeres, todo a raíz del consenso y del intercambio de opiniones y de buenas prácticas. Esto por supuesto ha repercutido en un aumento del bienestar para las mujeres.

'El CCM ha supuesto la creación de una red de mujeres en la que se han hecho muchas cosas, se han realizado muchas iniciativas que por sí solas no las hubiéramos hecho'

(Presidenta del CCM, 27 años, licenciada)

'El CCM ha supuesto un organismo de trasformación porque muchos programas y proyectos han visto la luz a raíz del CCM, sin él no podríamos enriquecernos unas de otras ni intercambiar ideas,

(Concejala de Igualdad, 40 años, Formación Profesional)

Los conflictos que se plantean a la hora de decidir actuaciones se delimitan por votación, previamente existe un debate en el que se analiza la cuestión y se dan opiniones consensuadas. Muchas veces los conflictos surgen entre las concejalías y las asociaciones que pueden tener intereses varios. En este sentido, como la relación entre los ayuntamientos y las asociaciones en general es buena sin entrar en pormenores, esto repercute en el funcionamiento del CCM. De hecho es notable apreciar que cuando esta relación está deteriorada la colaboración se ve mermada y también la participación activa en el CCM. Es importante reflejar que toda esta coordinación se vertebra desde el trabajo técnico del Área de Igualdad del Consorcio Guadalteba. Las asociaciones a través de sus propias reuniones periódicas recogen las propuestas y demandas que tengan para llevarlas al Consejo al igual que las Concejalías de Igualdad. La coordinadora provincial del IAM y de Diputación aprovechan estas reuniones para observar cómo se dinamiza el tejido asociativo de mujeres en los pueblos, las iniciativas que toman y para aportar información y recursos en materia de igualdad que desde sus instituciones puedan ofrecer. También su presencia sirve para descargar las demandas de asociaciones y concejalías.

Todos los testimonios recogidos desde las entrevistas coinciden en que el CCM ha supuesto desde su creación un antes y un después en la participación de las mujeres de la comarca. La importancia de crear un organismo en el que las mujeres decidan y 
propicien ellas mismas la coyuntura participativa es algo sin precedentes en la comarca el cual es valorado muy positivamente. Podemos concluir que la existencia del CCM ha transformado en gran medida la realidad de las mujeres y sirve como revulsivo para seguir participando ya que con todas las acciones que se acometen desde él son decisiones que toman las propias mujeres, tanto desde las concejalías como desde las asociaciones. Además de constituirse como un espacio único de decisión, valorativo y de impulso hacia las políticas de igualdad y las actuaciones para favorecer la vida de las mujeres. 


\section{Capítulo 5.- Motivaciones, percepciones y sentires}

En el presente capítulo analizaré desde el punto de vista emocional, las motivaciones que les llevan a participar en los diferentes ámbitos anteriormente expuestos, el cómo lo perciben y los sentimientos que emanan al llevar a cabo esas acciones. Destaco los sentimientos ambivalentes en cuanto a sentimientos que se traducen en comportamientos y que nos llevan a pensar en las contradicciones que aparecen sobre un mismo tema y sobre la puesta en práctica de su propio actuar.

\section{1.- Motivaciones}

Las motivaciones principales que les llevan a participar son el sentir que pueden 'hacer algo por sus pueblos' tanto a nivel asociativo como en la política desde los ayuntamientos. En el caso de las mujeres políticas su ambición en el $90 \%$ de los casos de las entrevistadas no pasa de lo local. Sin embargo, aunque ese protagonismo no lo sienten como tal y no reconozcan el poder que tienen para cambiar las cosas, sí existe esa motivación que las mueve a participar en el cambio.

Una de las desmotivaciones a participar en primera línea de la política municipal es el ser juzgadas; los patrones de género siguen siendo muy fuertes en el ámbito rural y existe ese miedo en muchas de ellas:

'Yo prefiero participar desde atrás y no meterme ni en política municipal ni en cargos directivos de la asociación, prefiero colaborar sin que se me vea mucho, que luego está todo criticado'

(Socia de Asociación de Mujeres, 46 años, sin estudios)

Los sentimientos que dibujan al expresarse son de satisfacción y realización por el trabajo hecho, sobre todo cuando la ayuda se hace directamente por demanda de alguna mujer que lo necesita. Se convierten en referentes de otras mujeres y esta cuestión es importantísima para el feminismo y la lucha por la igualdad.

En cuanto a la reflexión sobre sus motivaciones me doy cuenta que el factor que más influye es la capacidad de ayuda con que cuentan. Las preguntas implícitas nos llevan a pensar en los factores que influyen en considerarse como sujetos políticos con derecho propio. En el imaginario femenino sigue estando la premisa del 'estamos para servir' aunque se traduzca en motivación y hechos concretos. Por tanto podemos 
considerar que las mujeres siguen reproduciendo los patrones tradicionales de género en casi todos los aspectos que tienen que ver con sus vidas, ya sea en el ámbito privado o en el público.

\section{2.- Percepciones}

Perciben por un lado que su trabajo es importante pero no valoran lo suficiente su protagonismo como activadoras de cambio. Están ejerciendo la ciudadanía pero como no la perciben en sentido pleno, no pueden hacer una reflexión sobre su empoderamiento y el significado que supone en la transformación de la misma.

El relevo generacional en las asociaciones de mujeres es un aspecto que preocupa a la mayoría. En el caso de las asociaciones la percepción es de negativismo debido a la falta de relevo generacional y la falta de compromiso por parte de muchas socias que se niegan al relevo de la junta directiva, por lo tanto el peso de la responsabilidad siempre recae en las mismas produciendo la impotencia y la fatiga de no saber muy bien qué seguir aportando para que la participación sea alta.

'Las razones que nos llevaron a entrar en política son las mismas por las que empezamos en las asociaciones de mujeres. Estar en las asociaciones, después saltar a la política, son pasos que damos por un mismo motivo, el bien común'

(Ex concejala de Igualdad, 54 años, sin estudios)

La percepción del liderazgo no está muy delimitada, como tampoco la separación entre participación política en las asociaciones y desde los partidos por los motivos antes expuestos.

Muchas de estas mujeres han conseguido grandes logros sin tener el reconocimiento público de haberlo hecho y perciben que no se ha valorado su trabajo a nivel colectivo, si en el plano individual 


\section{3.- Sentires}

De nuevo los sentimientos ambivalentes que por un lado las llevan a sentir a veces que no son valoradas y al mismo tiempo sentir la gran satisfacción de poder ayudar y ser referentes de otras mujeres: 'el abrir camino'. A las mujeres jóvenes se les nota más liderazgo y una mayor autoestima, quizá porque ellas ya se han encontrado ese camino abierto que las demás han tenido que ir construyendo a fuerza de demostrar que podían y tenían que estar en los mecanismos de participación y de decisión de sus pueblos.

El reconocimiento personal de sentirse feministas no está aún consolidado, en cuanto a catalogarse como tales, muchas de ellas prefieren llamarse mujeres luchadoras con reivindicaciones de igualdad.

Existen sentimientos contradictorios también en cuanto al futuro, por un lado la esperanza y el empoderamiento 'podemos cambiar las cosas', por otro la desazón de que los pasos que se han dado no parecen tener una respuesta adecuada al esfuerzo invertido: 'a la hora de la verdad siempre perdemos las mujeres'. El sentir de las mayores por haber iniciado el camino y haber hecho algo importante para las futuras generaciones de mujeres jóvenes y la desesperanza de que éstas no tomen el relevo como se esperaba, sobre todo en las asociaciones.

'Ellas piensan que la igualdad está ya conseguida y están muy equivocadas, todas deberían saber nuestra historia para valorar el esfuerzo que se ha hecho y para que aprendan a luchar por que no le quiten lo conseguido y no vayamos para atrás como estamos yendo'

(Concejala de Igualdad, 40 años, Formación Profesional)

Lo que queda muy claro es la capacidad de trabajo y entrega que poseen, sobre todo las que han tenido menos apoyo a la hora de participar y por fin lo consiguen:

\section{'Yo quiero morir vivaii'}

(Ex concejala de Bienestar Social y primera cabeza de lista, 56 años) 


\section{V.- CONCLUSIONES}

El aumento de la participación de las mujeres ha traído más libertad y democracia para las mujeres, aunque aún queda mucho por recorrer, a día de hoy las mujeres rurales siguen conquistando espacios públicos y cada vez su protagonismo es más tenido en cuenta. En la comarca que nos ocupa, la irrupción de las mujeres en la vida política municipal ha supuesto un paso muy importante en un corto espacio de tiempo y esto quiere decir que a pesar de los obstáculos, las mujeres siguen estando ahí y cada vez en mayor proporción. La apuesta política desde los partidos políticos y desde la entrada en vigor de la ley de igualdad 2007 (ley orgánica 3/2007) en cuanto a garantizar la paridad, han favorecido la incorporación al espacio político de las mujeres del que podemos confirmar ha propiciado importantes cambios sociales y un interesante avance en la erradicación de las desigualdades entre los hombres y mujeres de nuestra comarca. La presencia de mujeres como alcaldesas ha sufrido un aumento muy considerable en el periodo estudiado; contamos en la actualidad con igual número de alcaldesas y alcaldes, siendo este dato muy significativo en cuanto a la paridad y el liderazgo; una conquista sin duda extraordinaria para la igualdad.

Comprobamos que la participación viene dada en primera instancia por el movimiento asociativo de mujeres y que poco a poco se van integrando en las estructuras políticas de sus pueblos. La participación en las asociaciones supone un trampolín para la entrada en la política municipal, la mayoría de concejalas y alcaldesas han formado o forman parte de asociaciones de mujeres. Éstas en muchas ocasiones representan a las mujeres políticas creando una red de colaboración entre concejalías de Igualdad y Asociaciones de Mujeres de las que sirven de escaparate a la ciudadanía.

La toma de conciencia de la lucha por la igualdad está interiorizada en las mujeres objeto de estudio, sin embargo el feminismo es catalogado como una palabra que provoca miedo. Los motivos van desde el propio desconocimiento histórico sobre el feminismo, hasta el rechazo a que las juzguen si ellas mismas se etiquetan como feministas ya que el término sigue siendo muy malinterpretado y provoca crispaciones. 
A pesar de que la actuación de las instituciones ha sido muy favorable para el impulso de la participación y el liderazgo en las mujeres rurales, encontramos una dependencia bastante alta respecto a ellas y las estrategias de agenda feminista que se impone desde la administración, como son las subvenciones, la celebración de actos reivindicativos dependiendo de las fechas a reivindicar, aspecto muy importante para visibilizar pero que muchas veces cuarta la independencia en la propia manera de actuar de las mujeres.

Podemos concluir que los patrones tradicionales de género siguen influyendo en la acción pública y política de las mujeres. Existe mucha ambivalencia en sus propios comportamientos que están marcados por la lucha por la igualdad por un lado, pero por otro el lastre de los papeles diferenciales de género siguen entrando en contradicción en muchas ocasiones. Estas contradicciones están inmersas en todos los aspectos analizados por lo tanto se hace necesario seguir trabajando el empoderamiento y el desarrollo personal en el colectivo de mujeres rurales para que tomen conciencia de estas ambivalencias y de la posibilidad de ejercer su participación y liderazgo de una manera asertiva y basada en mecanismos de sororidad sin tener en cuenta las presiones sociales a las que son sometidas.

Por otro lado, Consejo Comarcal de la Mujer ha sido y es un elemento de transformación y de visibilidad importantísimo en la comarca. Su existencia ha supuesto un revulsivo para provocar el aumento de la participación de las mujeres en esta zona, tanto a nivel de asociacionismo como de participación política en los ayuntamientos. Este organismo ha vertebrado actuaciones a nivel comarcal, ha permitido poner en marcha estrategias y acciones dirigidas a aumentar el protagonismo, el empoderamiento y la autoestima de las mujeres y crear conciencia sobre su liderazgo. Por tanto podemos decir que la permanencia del CCM es vital para seguir trabajando en este sentido. 


\section{VI.- REFERENCIAS BIBLIOGRÁFICAS}

AMORÓS PUENTE, Celia (1990). Mujer y participación política. Pág. 197-115 en Participación política de las mujeres, compilado por J. Astelarra. Madrid: Centro de Investigaciones Sociológicas.

ASTELARRA BONOMI, Judith (1990). Participación política de las mujeres (Comp.). Madrid: Centro de Investigaciones Sociológicas.

BARBERÁ HEREDIA, Esther (2000). Invisibilidad de las mujeres y representaciones de poder. Pp. 43-59, en Las mujeres del año 2000: hechos y aspiraciones. Madrid: Instituto de la Mujer, Ministerio de Trabajo y Asuntos Sociales.

BAYLINA FERRÉ, Mireia y SALAMAÑA SERRA, Isabel (2006). El lugar del género en la geografía rural. Boletín de la A.G.E. n 41-2006.

BARRERÈ UNZUETA, Ma Ángeles (2010). La interseccionalidad como desafío al mainstreaming de género en las políticas públicas. R.V.A.P. núm. 87-88/2010. Págs. 225-252 ISSN: 0211-9560

BLÁZQUEZ VILAPLANA, Belén (2005). Liderazgo político y género: análisis del caso andaluz desde otra perspectiva. VII Congreso Español de Ciencia política y de la Administración: Democracia y Buen Gobierno.

BAYONA SÁEZ, Cristina (1999). Las Iniciativas NOW y LEADER II han facilitado la participación de la mujer en el desarrollo rural. Pp. 6-7. En Actualidad Leader. Núm. 5. Unidad Española del Observatorio Europeo LEADER. Madrid. 1999.

BENHABIB, Seyla (2006). Las Reivindicaciones de la Cultura. Igualdad y diversidad en la era global. Buenos Aires: Katz Editores.

BEAUVOIR, Simone (2005). El Segundo Sexo. Madrid: Cátedra

BRANDEN, Nathaniel (2007). Los seis pilares de la autoestima. Madrid: Paidós Ibérica.

CALATRAVA REQUENA, Javier (1997). Importancia de la integración de la mujer en los procesos de desarrollo. Ponencia presentada a las Jornadas 'La Mujer: clave del Desarrollo Rural' Campanillas (Málaga), Octubre 1997. Consejería de Agricultura y Pesca-Junta de Andalucía

CAMAS GARCÍA, Francisco (2013). La presencia política de las mujeres en los municipios españoles. Actas del XI Congreso Español de Sociología celebrado en Madrid del 10 al 12 de julio de 2013. Madrid: Federación Española de Sociología.

CAPO GIOL, Jordi (1992). 'La elite local en España', Revista de Estudios Políticos nº76, pág. 127-143. 
COBO BEDIA, Rosa (2000). 'Política Feminista y Democracia Paritaria'. Leviatán, Revista de hechos e ideas $\mathrm{n}^{\circ} 80$, pág. 85-99.

COBO BEDIA, Rosa (1993). 'Mujer y Poder'. Revista Internacional de Filosofía Política, no 1. Pág. 165-177.

CONDE, Rosa; MARTÍNEZ, Isabel; MIYARES, Alicia y VALCARCEL, Amelia (eds.). 'Cómo salir de la crisis. El papel de las mujeres'. V Encuentro de Mujeres Líderes Iberoamericanas (2010). Fundación Carolina, Documento de Trabajo n. ${ }^{\circ} 45$

CONSEJERÍA DE AGRICULTURA Y PESCA (2000). Guía de Desarrollo Rural. Mujeres en el Desarrollo Rural. Empresa Pública para el Desarrollo Agrario y Pesquero de Andalucía. Junta de Andalucía. Córdoba.

CONSEJERÍA DE AGRICULTURA, PESCA Y ALIMENTACIÓN. Plan de Género en las zonas rurales para el 2009-2015

CONSEJERÍA DE AGRICULTURA Y PESCA. Documento Nueva Estrategia Rural para Andalucía (NERA) 2007-2013. Sevilla.

CRUCES ROLDÁN, Cristina y PALENZUELA CHAMORRO, Pablo (2011). 'Mujeres políticas y Desarrollo Rural en Andalucía'. Revista Internacional de Sociología (RIS) Vol.69, n² 2, Mayo-Agosto, 487-515

CRUZ SOUZA, Fátima (2006). Género, psicología y desarrollo rural: la construcción de nuevas identidades. Madrid: Ministerio de Agricultura, Pesca y Alimentación, Serie Estudios 163

CRUZ SOUZA, Fátima (2009). 'Empoderamiento y participación social de las mujeres en el medio rural'. Revista Agricultura Familiar en España. Pág. 110-115

DE LA FUENTE, María (2011). 'Del derecho al sufragio a la plena participación politica de las mujeres'. Foro para la igualdad Emakunde. Marzo 2011

DELGADO SOTILLOS, Irene. y JEREZ, Miguel (2008). “Mujer y política en España: un análisis comparado de la presencia femenina en las asambleas legislativas (19772008)" Revista Española de Ciencia Política 19: 41-78

DÍAZ MÉNDEZ, Cecilia (2005). Aproximaciones al arraigo y al desarraigo femenino en el medio rural: mujeres jóvenes en busca de una nueva identidad rural. Papers 75:63-84.

Documento Nueva Estrategia Rural del Guadalteba 2007-2013. Málaga: Grupo de Acción Local Guadalteba.

Documento Plan Estratégico para la Igualdad de Mujeres y Hombres en Andalucía 2010-2013. Sevilla: Instituto andaluz de la Mujer, Consejería para la Igualdad y el Bienestar Social. Págs. 71-80.

DURÁN HERAS, Ma Ángeles y ROGERO GARCÍA, Jesús (2009). La Investigación sobre el uso del tiempo. Madrid: Centro de Investigaciones Sociológicas. Pág. 215. 
DURÁN, Mª Angeles (1986). La jornada interminable. Barcelona: Icaria.

EXPÓSITO MOLINA, Carmen (2012). ¿Qué es eso de Interseccionalidad? Aproximación al tratamiento de la diversidad desde la perspectiva de género en España, Investigaciones Feministas, vol. 3 203-222

FEDERACIÓN ESPAÑOLA DE MUNICIPIOS Y PROVINCIAS (FEMP). 2007. Estudio del impacto de la Ley Orgánica 3/2007 para la igualdad efectiva de mujeres y hombres en la representación de las mujeres en el ámbito de la política local. Madrid: FEMP.

FISCHLER, F. y FLYNN, P. (1995). La mujer en las zonas rurales: la perspectiva de la UE. El Campo. Núm. 133. Servicio de Estudios del Banco Bilbao-Vizcaya. Bilbao. Pp. 321-324.

FORUM DE POLÍTICA FEMINISTA (2012). 25 Años de Forum de Política Feminista y de Feminismo n1987-2012. ¿Abriendo nuevo ciclo? Las Asociaciones de Mujeres ante el Empleo, la Violencia de Género y la Participación. XXII Taller de Política Feminista. Madrid: Forum de Política Feminista.

FOUCAULT, Michel (1999). Estrategias de Poder. Barcelona: Paidos.

GALERA VICTORIA, Adoración (2012). La actividad legislativa en materia de igualdad efectiva entre hombres y mujeres. Sevilla: Fundación Centro de Estudios Andaluces.

GÁLVEZ, Lina y MUÑOZ Mauricio (2010). Trabajo, Bienestar y Desarrollo de las Mujeres en el ámbito rural andaluz: estudio para el diseño de políticas de igualdad y desarrollo. Instituto Andaluz de la Mujer. Sevilla

GARCÍA BARTOLOMÉ, JM. (1999). "Mujeres rurales, sociedad civil y desarrollo rural". En Instituto de la Mujer. Mujeres y sociedad rural. Entre la inercia y la ruptura. Madrid. Ministerio de Trabajo y Asuntos Sociales. Instituto de la Mujer. Pp.64-79.

GARCÍA RAMÓN, Maria Dolors y BAYLINA FERRÉ, Mireia (Eds.). 2000. El nuevo papel de las mujeres en el desarrollo rural. Barcelona: Oikos-Tau.

GARCÍA SANZ, Benjamín (2003). 'La mujer rural en los procesos de desarrollo de los pueblos'. Revista del Ministerio de Trabajo y Asuntos Sociales.

GENOVESE Michael (1997). Mujeres Líderes en Política. Modelos y prospectivas. Madrid: Narcea.

GIARDIN Y GALÁN, Federico José (2001). 'El desarrollo rural en la provincia de Málaga'. Jábega. Núm. 87. Pp. Exima. Diputación Provincial de Málaga.

DIPUTACIÓN DE GRANADA (2003). Informe de la Investigación sobre la participación según género en la Administración Pública Local en el Medio Rural. Área de la Mujer Diputación de Granada.

INSTITUTO DE LA MUJER (2005): Mujeres en cifras, Madrid, Instituto de la Mujer. 
INSTITUTO DE LA MUJER (1999). Políticas públicas de apoyo a las mujeres rurales. En García Bartolomé, J.M. 1999: Mujeres y sociedad rural: entre la inercia y la ruptura. Instituto de la Mujer. Ministerio de Asuntos Sociales. Madrid. Pp. 155-171.

INSTITUTO DE LA MUJER (2000): Congreso Europeo de mujeres rurales. Madrid, 16 y 17 de diciembre de 1999. Ponencias e intervenciones en mesas redondas. Ministerio de Trabajo y Asuntos Sociales. Madrid. 221 pp.

INSTITUTO DE LA MUJER (Comp.). 2009. Pacto entre Géneros y Políticas Públicas. Género y Cohesión Social. Madrid: Ministerio de Igualdad.

INSTITUTO ANDALUZ DE LA MUJER. Plan de Igualdad de Oportunidades entre Mujeres y Hombres en el Medio Rural 2007-2013

INSTITUTO ANDALUZ DE LA MUJER, Consejería para la igualdad y bienestar social. Aproximación a la realidad de mujeres y hombres en Andalucía 2010

INSTITUTO ANDALUZ DE LA MUJER (2010). Los Consejos Locales de la Mujer en Andalucía. Diagnóstico de la situación.

LAGARDE Y DE LOS RÍOS, Marcela (1999). Claves feministas para el poderío y la autonomía de las mujeres. Sevilla: Instituto Andaluz de la Mujer.

LAGARDE Y DE LOS RÍOS, Marcela (2000). Claves feministas para la autoestima de las mujeres. Madrid: Ed. horas y horas

LANGREO NAVARRO, A. (1995). 'Participación simbólica'. Mujeres. Núm. 17. Pp. 12-13.

LARRUBIA VARGAS, Remedios y NAVARRO RODRÍGUEZ, Susana (2001). 'Las estrategias europeas para el desarrollo local en el medio rural malagueño'. Jábega Núm. 87. Pp. Málaga. 2001.

PALENZUELA CHAMORRO, Pablo y CRUCES ROLDÁN, Cristina (2009). 'La participación política de las mujeres en el medio rural'. Revista Agricultura Familiar en España, pág. 204-214

PHILLIPS, Anne (1995). The Politics of Presence. New York: Oxford University Press.

PITKIN, H. (1985). El concepto de representación. Madrid: Centro de Estudios Constitucionales.

POLO GONZÁLEZ, María Eugenia y SANTIAGO BARNÉS, Jorge (2011). Liderazgo, Mujer y Política. Salamanca: Amarú.

QUINTANA, Juan; CAZORLA, Adolfo y MERINO, Julio (1999). Desarrollo rural en la Unión Europea: modelos de participación social. Madrid: Ministerio de Agricultura, Pesca y Alimentación.

MINISTERIO DEL INTERIOR (2007). Elecciones locales 2007. El impacto de la Ley Orgánica 3/2007, de 22 de marzo, para la igualdad efectiva de mujeres y hombres. Madrid: Ministerio del Interior, Dirección General de Política Interior. 
MINISTERIO DEL INTERIOR (2011). Elecciones locales 2011. El impacto de la Ley Orgánica 3/2007, de 22 de marzo, para la igualdad efectiva de mujeres y hombres. Madrid: Ministerio del Interior, Dirección General de Política Interior.

MOYANO ESTRADA, Eduardo (2005). "Nuevas orientaciones de la política europea de desarrollo rural." Pp. 75-88 en XII Informe Socioeconómico de la Agricultura familiar en España. Fundación de Estudios Rurales. Madrid.

MURARO, Luisa (2013). Autorità. Torino: Rosenberg \&Sellier.

NEWBY, Howard y SEVILLA GUZMÁN, Eduardo (1983). Introducción a la Sociología Rural. Madrid: Alianza Universidad.

NIETO FIGUERAS, Cristina (2004). 'Las Mujeres empresarias y el Desarrollo Rural. Experiencias en los municipios malagueños’. Tesis Doctoral. Universidad de Málaga.

PALENZUELA CHAMORRO, Pablo y CRUCES ROLDÁN, Cristina (2009). 'La Participación Política de las Mujeres en el Medio Rural'. Revista Agricultura Familiar en España $N^{o} 204$.

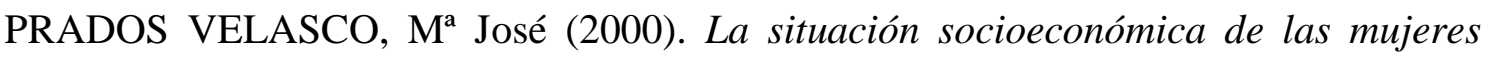
rurales en España. Sevilla: Consejería de Agricultura y Pesca, Junta de Andalucía.

ORTEGA LÓPEZ, Teresa María (2007). 'Las Miserias del fascismo rural'. Revista Historia Agraria no 43, diciembre 2007 pp.531-553.

RAMOS Amparo, BARBERÁ Ester, SARRIÓ Maite (2003). 'Mujeres directivas, espacio de poder y relaciones de género'. Anuario de Psicología vol. 34, nº, 2, págs. 267-278.

RICO GONZÁLEZ, Margarita (2013). 'La mujer y su relevancia en el desarrollo rural español'. Primer Simposio Nacional de Mujeres Rurales. Teruel 18 y 19 de octubre de 2013.

RODRÍGUEZ GARCÍA, M ${ }^{\mathrm{a}}$ Jesús (2013). Género y Política Municipal. Representación Descriptiva y Agenda de Género en los Municipios Españoles. Sevilla: Centro de Sociología y Políticas Locales Universidad Pablo Olavide.

RODRÍGUEZ GARCÍA, Ma Jesús (2012). 'Los Consejos Locales de la Mujer en municipios españoles. Diagnóstico sobre sesgos de inclusividad y agenda'. Revista Española de Ciencia Política” Núm. 29, pp. 107-128.

RODRÌGUEZ GARCÍA, Ma Jesús y NAVARRO YÁÑEZ, Clemente (2012). 'La feminización de la dinámica política municipal. El caso de los municipios españoles'. Revista Internacional de Sociología $N^{o} 70$ (1) pp. 181-201.

RODRÍGUEZ GUERRERO, Rafael (2011). Diputadas. La Mujer en el Parlamento de Andalucía y en la Política Local, Autonómica y Nacional. Parlamento de Andalucía.

ROLDÁN GARCÍA, Elena (2004). Género, Políticas Locales e Intervención Social. Madrid: Editorial Complutense. 
ROSE O. Sonya (2012). ¿Qué es Historia de Género?. Madrid: Alianza Editorial.

ROSSILLI, Mariagrazia (2001). Políticas de Género en la Unión Europea (coord.). Madrid: Narcea.

RUBIO CASTRO, Ana (1997). Feminismo y Ciudadanía. Sevilla: Instituto andaluz de la Mujer.

RUÍZ AVILÉS, Pedro (2000). Bases para la acción social y planificación estratégica del desarrollo rural. Junta de Andalucía. Sevilla. P. 22.

SAN PEDRO GALLEGO, Rosario (1996). 'Género y ruralidad. Las mujeres ante el reto de la desagrarización'. Madrid: Instituto de la Mujer

SÁNCHEZ HERNÁNDEZ, María F. (2003). 'Liderazgo Político de Mujeres. Desde la Transición hacia la Democracia Paritaria'. Sevilla: Instituto Andaluz de la Mujer.

SÁNCHEZ-MUROS, Sonsoles Patricia y JIMÉNEZ RODRIGO, Maria Luisa (2013). 'Mujeres rurales y participación social: análisis del asociacionismo femenino en la provincia de Granada (España)'. Cuadernos de Desarrollo Rural, 10 (72), 223-242.

SÁNCHEZ-ORO SÁNCHEZ, Marcelo; MORÁN MORÁN, María Irene y BLANCO GREGORI, Rocío (2010). Procesos electorales locales y presencia política de mujeres: el caso de dos comarcas en la provincia de Cáceres.

SERRANO AMADOR, Celia. Jornadas Red de Mujeres Rurales y Urbanas: un espacio de desarrollo económico y social. Fuente Vaqueros 2012

SIMÓN RODRÍGUEZ, Elena (1999). Democracia Vital. Mujeres y Hombres hacia la plena ciudadanía. Madrid: Narcea.

URIARTE BENGOETXEA, Edurne y ELIZONDO LOPETEGUI Arantxa (1997). 'Mujeres en Política' (coord.). Barcelona: Ariel.

VALCÁRCEL y DE QUIROS, Amelia (1997). La política de las mujeres. Madrid. Cátedra.

VALCÁRCEL y DE QUIROS, Amelia (2001). "La presencia de las mujeres en la toma de decisiones relevantes: los retos del futuro." Pp. en Las mujeres en el año 2000: hechos y aspiraciones. Madrid: Ministerio de Trabajo y Asuntos Sociales, Instituto de la Mujer

VERGE MESTRE, Tania (2008). 'Cuotas voluntarias y legales en España. La paridad a examen', Revista Española de Investigaciones Sociológicas 123:123-150

VILLARIÑO PÉREZ, Montserrat (1995). 'Las mujeres rurales como artífices de la pluralidad'. El Campo. Núm. 133. Servicio de Estudios del Banco Bilbao-Vizcaya. Bilbao. Pp. 11-24. 


\section{Recursos Web:}

INSTITUTO ANDALUZ DE LA MUJER: Centro de documentación Maria Zambrano:

http://www.juntadeandalucia.es/institutodelamujer/index.php/centrodedocume $\underline{\text { ntacion }}$

ONU MUJERES. Sistema de Información Electoral desde la perspectiva de género,http://www.un-instraw.org/es/ggppl-phase-1/news/sistema-de informacionelectoral.html (Última visita 18/08/2014).

INSTITUTO EUROPEO DE LA IGUALDAD DE GÉNERO. 2012. Fundamentos del índice de igualdad de género para Europa, http://www.eige.europa.eu/es/content/document/rationalefor-the-gender-equality-indexfor-europe (Última visita 12/08/2014).

RED DE MUJERES RURALES Y URBANAS:

http://www.redmujeresruralesyurbanas.com/ (Última visita 12/09/2014)

OBSERVATORIO DE IGUALDAD EN EL MEDIO RURAL (2007/2008): http://www.observatoriodegenero.org/ (Última visita 28/06/2014)

CONSEJERÍA DE AGRICULTURA Y PESCA, JUNTA DE ANDALUCÍA: http://www.juntadeandalucia.es/agriculturaypesca/portal/areas-tematicas/desarrollorural-sostenible/perspectiva-de-genero-en-las-politacas-de-desarrollo-rural/diamundial-de-las-mujeres-rurales/index.html (Última visita 29(07/2014)

ORGANIZACIÓN DE LAS NACIONES UNIDAS PARA LA AGRICULTURA Y LA ALIMENTACIÓN/GÉNERO: http://www.fao.org/americas/perspectivas/genero/es/ (Última visita 18/08/2014)

COMISIÓN EUROPEA ESTRATEGIA 2020:

http://ec.europa.eu/europe2020/index_es.htm (Última visita: 12/07/2014) 


\section{VII.- ANEXOS}

\section{ANEXO 1:}

\section{TABLA 1.- PRESENCIA DE MUJERES EN LISTAS ELECTORALES ELECCIONES MUNICIPALES 2003}

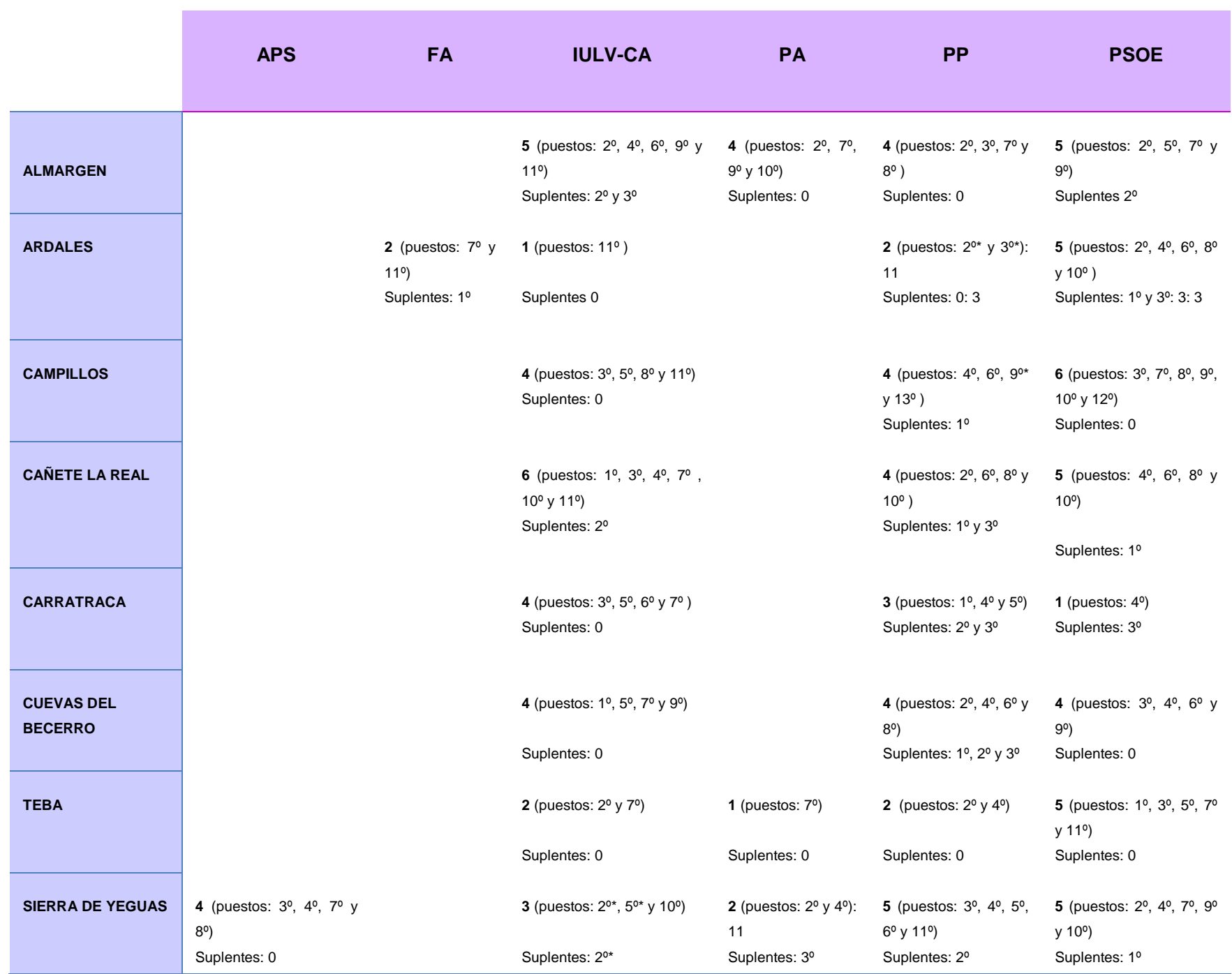

* Independiente (ejemplo $5^{\text {*}}$ quinto puesto en las listas por independiente).

Fuente: Boletines Oficiales de la Provincia (BOPs) y elaboración propia

APS: Asociación del Pueblo Serrano

FA: Falange Auténtica

IULV-CA: Izquierda Unida Los Verdes-Convocatoria por Andalucía

PA: Partido Andalucista

PP: Partido Popular

PSOE: Partido Socialista Obrero Español 
TABLA 2.- PRESENCIA DE MUJERES EN LISTAS ELECTORALES ELECCIONES MUNICIPALES 2007

\begin{tabular}{|c|c|c|c|c|c|c|}
\hline & FA & GSI & IULV-CA & PA & PP & PSOE \\
\hline ALMARGEN & & & $\begin{array}{l}2 \text { (puestos } 10^{\circ} \text { y } \\
\left.11^{\circ}\right) \\
\quad \text { Suplentes: } 0\end{array}$ & & $\begin{array}{l}5 \text { (puestos } 2^{\circ}, 4^{\circ}, 6^{\circ}, \\
8^{\circ} \text { y } 10^{\circ} \text { ) } \\
\text { Suplente: } 1^{\circ}\end{array}$ & $\begin{array}{l}6 \text { (puestos } 2^{\circ}, 3^{\circ}, \\
\left.5^{\circ}, 6^{\circ}, 7^{\circ} \text { y } 9^{\circ}\right) \\
\text { Suplentes: } 0\end{array}$ \\
\hline ARDALES & $\begin{array}{l}4 \text { (puestos } 3^{\circ}, 7^{\circ}, 9^{\circ} \\
\text { y } 11^{\circ} \text { ) } \\
\text { Suplentes: } 1^{\circ} \text { y } 3^{\circ}\end{array}$ & & $\begin{array}{l}5 \text { (puestos } 2^{\circ}, 4^{\circ} \\
\left.5^{\circ}, 7^{\circ} \quad \text { y } 9^{\circ}\right) \\
\text { Suplentes: } 0\end{array}$ & & 2 (puestos $2^{\circ}$ y $5^{\circ}$ ) & $\begin{array}{l}5 \text { (puestos } 2^{\circ}, 4^{\circ}, \\
\left.6^{\circ}, 8^{\circ} \text { y } 10^{\circ}\right) \\
\text { Suplentes: } 1^{\circ} \text { y } 3^{\circ}\end{array}$ \\
\hline CAMPILLOS & & & $\begin{array}{l}5 \text { (puestos } 3^{\circ}, 5^{\circ *} \\
7^{\circ}, 9^{\circ *} \text { y } 12^{\circ *} \\
\text { Suplentes: } 1^{\circ *}\end{array}$ & & $\begin{array}{l}6 \text { (puestos } 4^{\circ}, 5^{\circ}, 8^{\circ}, \\
10^{\circ}, 11^{\circ *}, 12^{\circ} \text { ) } \\
\text { Suplentes: } 2^{\circ}\end{array}$ & $\begin{array}{l}6\left(3^{\circ}, 5^{\circ}, 7^{\circ}, 9,11^{\circ}\right. \\
\left.\text { y } 13^{\circ}\right) \\
\text { Suplentes: } 2^{\circ}\end{array}$ \\
\hline CAÑETE LA REAL & & $\begin{array}{l}2 \text { (puestos } 6^{\circ} \text { y } \\
8^{\circ} \text { ) } \\
\text { Suplentes: } 2^{\circ}\end{array}$ & $\begin{array}{l}7 \text { (puestos: } 1^{\circ}, 3^{\circ} \\
\left.5^{\circ}, 6^{\circ}, 7^{\circ}, 9^{\circ *} \text { y } 10^{\circ}\right) \\
\text { Suplentes: } 1^{\circ}\end{array}$ & & $\begin{array}{l}4 \text { (puestos: } 1^{\circ}, 3^{\circ}, 6^{\circ} \text { y } \\
\left.10^{\circ}\right) \\
\text { Suplentes: } 1^{\circ}\end{array}$ & $\begin{array}{l}5 \text { (puestos: } 3^{\circ}, 5^{\circ}, \\
6^{\circ}, 8^{\circ} \text { y } 11^{\circ} \text { ) } \\
\text { Suplentes: } 2^{\circ}\end{array}$ \\
\hline CARRATRACA & & & $\begin{array}{l}3 \text { (puestos: } 3^{\circ}, 5^{\circ} \text { y } \\
\left.6^{\circ}\right) \\
\text { Suplentes: } 2^{\circ} \text { y } 3^{\circ}\end{array}$ & & $\begin{array}{l}4 \text { (puestos: } 1^{\circ}, 4^{\circ}, 5^{\circ \star} \\
\left.\text { y } 7^{\circ \star}\right) \\
\text { Suplentes: } 1^{\circ} \text { y } 2^{\circ}\end{array}$ & $\begin{array}{l}2 \text { (puestos: } 2^{\circ} \text { y } 5^{\circ} \\
\text { Suplentes: } 0\end{array}$ \\
\hline $\begin{array}{l}\text { CUEVAS DEL } \\
\text { BECERRO }\end{array}$ & & & $\begin{array}{l}5 \text { (puestos: } 1^{\circ}, 4^{\circ} \\
\left.6^{\circ}, 8^{\circ} \text { y } 9^{\circ}\right) \\
\text { Suplentes: } 0\end{array}$ & & $\begin{array}{l}4 \text { (puestos: } 3^{\circ}, 5^{\circ}, 6^{\circ} \text { y } \\
\left.9^{\circ}\right) \\
\text { Suplentes: } 0\end{array}$ & $\begin{array}{l}4 \text { (puestos: } 3^{\circ}, 5^{\circ}, \\
\left.8^{\circ} \text { y } 9^{\circ}\right) \\
\text { Suplentes: } 1^{\circ}, 2^{\circ} \text { y } \\
3^{\circ}\end{array}$ \\
\hline SIERRA DE YEGUAS & & & $\begin{array}{l}4 \text { (puestos: } 1^{\circ}, 4^{\circ}, \\
\left.6^{\circ} \text { y } 8^{\circ}\right) \\
\text { Suplentes: } 0\end{array}$ & $\begin{array}{l}4 \text { (puestos: } 3^{\circ}, 6^{\circ}, \\
\left.7^{\circ} \text { y } 8^{\circ}\right) \\
\text { Suplentes: } 0\end{array}$ & $\begin{array}{l}4 \text { (puestos: } 2^{\circ}, 7^{\circ}, 9^{\circ} \text { y } \\
\left.11^{\circ}\right) \\
\text { Suplentes: } 5^{\circ}\end{array}$ & $\begin{array}{l}6 \text { (puestos: } 1^{\circ}, 3^{\circ}, \\
5^{\circ}, 8^{\circ}, 10^{\circ} \text { y } 11^{\circ} \text { ) } \\
\text { Suplentes: } 0\end{array}$ \\
\hline TEBA & & & $\begin{array}{l}2 \text { (puestos: } 2^{\circ} \text { y } 9^{\circ} \text { ) } \\
\text { Suplentes: } 0\end{array}$ & & $\begin{array}{l}6 \text { (puestos: } 1^{\circ}, 3^{\circ}, 5^{\circ}, \\
\left.7^{\circ}, 9^{\circ} \text { y } 10^{\circ}\right) \\
\text { Suplentes: } 1^{\circ} \text { y } 3^{\circ}\end{array}$ & $\begin{array}{l}5 \text { (puestos: } 1^{\circ}, 3^{\circ}, \\
6^{\circ}, 9^{\circ} \text { y } 11^{\circ} \text { ) } \\
\text { Suplentes: } 0\end{array}$ \\
\hline
\end{tabular}

* Independiente (ejemplo 5**: quinto puesto en las listas por independiente). Fuente: Boletines Oficiales de la Provincia Fuente: Boletines Oficiales de la Provincia (BOPs) y elaboración propia

FA: Falange Auténtica

GSI: Agrupación de Electores Grupo Social Independiente

IULV-CA: Izquierda Unida Los Verdes-Convocatoria por Andalucía

PA: Partido Andalucista

PP: Partido Popular

PSOE: Partido Socialista Obrero Español 


\section{TABLA 3.- PRESENCIA DE MUJERES EN LISTAS ELECTORALES ELECCIONES MUNICIPALES 2011}

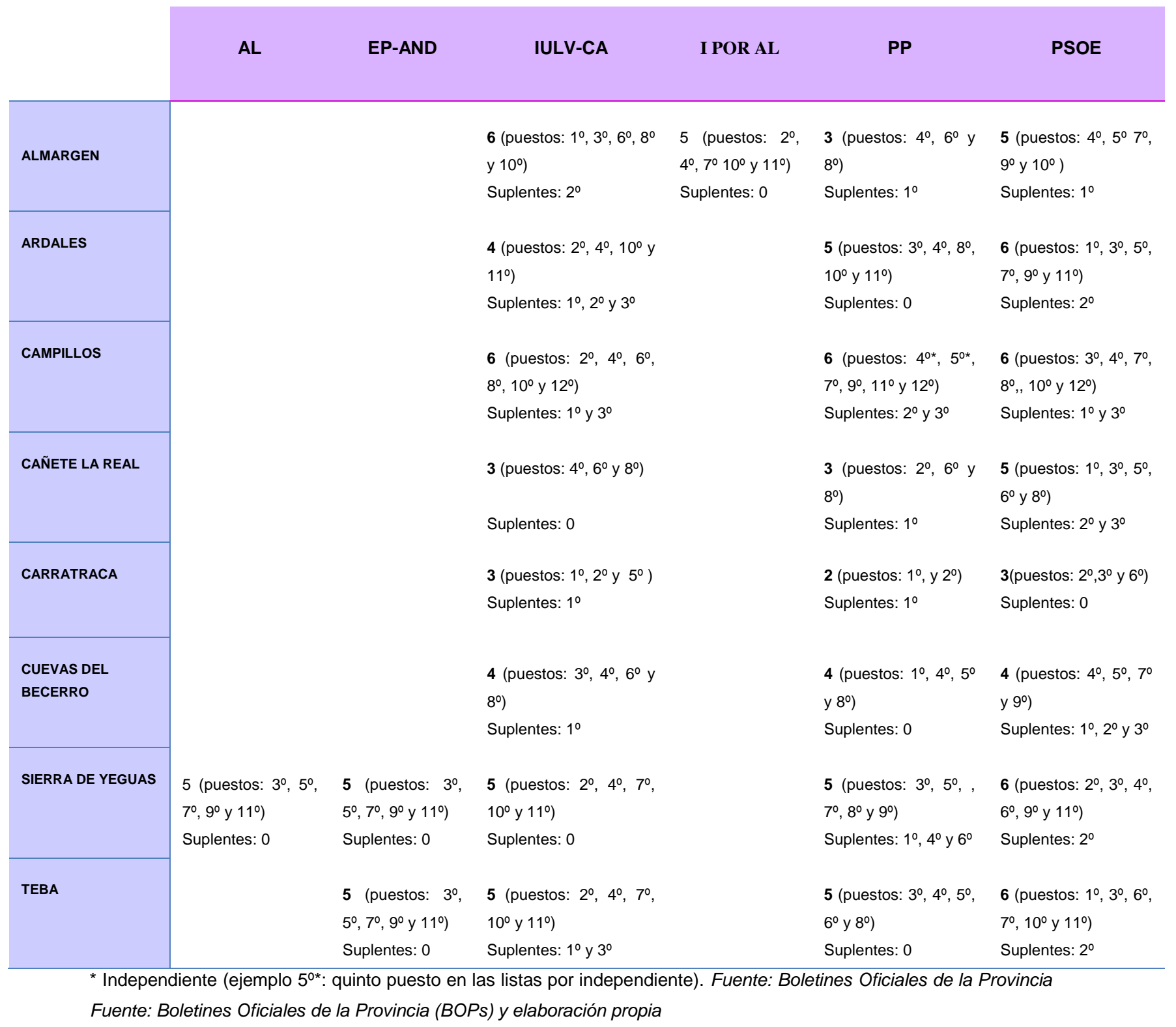

AL: Alternativa Local por Sierra de Yeguas

EP-AND: Espacio Plural Andaluz

I POR AL: Independientes por Almargen

IULV-CA: Izquierda Unida Los Verdes-Convocatoria por Andalucía

PP: Partido Popular

PSOE: Partido Socialista Obrero Español 


\section{ANEXO 2:}

\section{REGLAMENTO DEL CONSEJO DE LA MUJER DEL GUADALTEBA}

\section{CAPITULO I: DISPOSICIONES GENERALES.}

\section{Artículo 1.- OBJETO:}

El presente Reglamento tiene por objeto la regulación del Consejo de la Mujer, que se halla integrado en el Consorcio Guadalteba.

\section{Artículo 2.- NORMATIVA APLICABLE:}

El Consejo de la Mujer se crea al amparo de lo establecido en el árticulo 131 del Reglamento de Organización, Funcionamiento, y Régimen Jurídico de las Entidades Locales, rigiéndose por lo establecido en el presente Reglamento, asi como en la restante normativa sobre Régimen Local vigente, y lo establecido en los Estatutos del propio Consorcio Guadalteba. Es un órgano colegiado de caracter consultivo y participativo con funciones de impulsar, potenciar y gestionar la promoción de la mujer en el área geográfica del Consorcio Guadalteba.

\section{Artículo 3.- NATURALEZA Y CAPACIDAD JURIDICA:}

El Consejo de la Mujer es un órgano colegiado de carácter consultivo y participativo, integrado en el Consorcio Guadalteba, y sin personalidad ni capacidad jurídica propia.

\section{Artículo 4.- DOMICILIO:}

El Consejo de la Mujer tendrá su sede en la propia del Consorcio Guadalteba.

\section{Artículo 5.- AMBITO DE ACTUACION:} Guadalteba.

El Consejo de la Mujer extenderá su actuación al área geográfica del Consorcio

\section{Artículo 6.- FUNCIONES:}

Son atribuciones de dicho Consejo:

a) Informar al Consorcio, así como a las Corporaciones integradas en el mismo, sobre temas específicos de la mujer, así como proponer alternativas concretas a los problemas que puedan planteárseles, para que sean tratados por los entes municipales competentes. aprobados.

b) Participar en el seguimiento de la gestión municipal en los asuntos

c) Formulación de trabajos y propuestas en el ámbito propio de actuación.

d) Colaborar y/o participar en la elaboración de estudios, planes y programas de los órganos locales cuando así sea requerido por estos. 
e) Elevar a los órganos locales competentes las propuestas y conclusiones elaboradas.

f) Participar en la elaboración, programación y seguimiento de actuaciones del Centro Comarcal de Información de la Mujer del Consorcio Guadalteba.

\section{CAPITULO II: COMPOSICIÓN Y ÓRGANOS DE GOBIERNO.}

\section{Artículo 7.- COMPOSICIÓN:}

Formarán este Consejo:

a) Nueve miembros, libremente designados/as y cesados/as por las Corporaciones Locales de entre sus miembros, integradas en el Consorcio Guadalteba, a razón de un nombramiento por miembro consorciado.

b) Un miembro de apoyo técnico, siendo persona integrada en el Centro de Información a la Mujer del Consorcio Guadalteba, designado/a y cesado/a por la presidencia del Consorcio.

c) Presidente/a

d) Vicepresidente/a.

e) Secretario/a.

f) Gerente del Consorcio.

g) Representante de cada una de las asociaciones de mujeres y Federaciones existentes en los municipios que integran el Consorcio.

En cualquier caso, el/la Presidente/a podrá recabar en cualquier momento, la participación de personal especializado, que por su labor o experiencia, considere oportuna su puntual asistencia a sesiones concretas, en las que intervendrá con voz y sin voto.

\section{Artículo 8.- ÓRGANOS DE GOBIERNO:}

Serán órganos de gobierno del Consejo:

-Presidente/a.

-Vicepresidente/a.

-Pleno.

\section{Artículo 9.- PRESIDENTE/A:}

Será Presidente/a del Consejo, el/la propio del Consorcio en cada momento, siendo sus funciones las de ostentar la representación legal del Consejo, dirigir el gobierno y administración del mismo, vigilar el cumplimento de los asuntos de aquél y convocar y levantar las sesiones del Pleno.

\section{Artículo 10.- VICEPRESIDENTE/A:}

Será función del/a Vicepresidente/a asistir los asuntos que sean competencia del/a Presidente/a, a quien sustituirá en caso de ausencia, vacante o enfermedad. 


\section{Artículo 11.- DEL PLENO:}

El Consejo de la Mujer se reunirá en Pleno, constituido por todos los miembros señalados anteriormente.

\section{Artículo 12.- DEL GERENTE:}

Su función será la gestión de las medidas que se consideren oportunas para el desarrollo eficaz de los asuntos, en los ordenes económicos, administrativos y técnicos bajo la autoridad del/a Presidente/a.

\section{Artículo 13.- DEL/A SECRETARIO/A:}

El/la secretario/a del Consorcio Guadalteba lo será tambien de este Consejo, pudiendo delegar por escrito en el personal técnico del Centro de Información a la Mujer, y correspondiéndole levantar acta de las sesiones del Pleno.

\section{CAPITULO III: RÉGIMEN DE SESIONES}

\section{Artículo 14.- SESIONES:}

El Consejo en pleno podrá reunirse en:

- Sesión Ordinaria: una vez cada tres meses, previa convocatoria de todos/as sus componentes.

- Sesión Extraordinaria: cuando lo solicite la cuarta parte de sus miembros, para la sesión de constitución del Consejo, así como cuando lo acuerde el/la Presidente/a.

\section{Artículo 15.- CONVOCATORIAS:}

Para toda clase de sesiones, excepto cuando la urgencia de los asuntos a tratar asi lo exijan, se efectuará al menos con cuatro días de antelación, indicando día, hora y lugar de celebración de aquellas, el orden del día, y acompañándose cuantos documentos sean necesarios para el mejor conocimiento de los asuntos a tratar.

En caso de urgencia se podrá reducir el plazo de convocatoria, siempre que esté debidamente justificado.

\section{Artículo 16.- QUORUM DE ASISTENCIA:}

En primera convocatoria, se considerará legalmente constituido el Consejo en pleno, siempre que estén presentes la mayoría de sus miembros.

En segunda convocatoria bastará con cualquier número de asistentes/as, y se reunirá media hora más tarde de la señalada para la primera. En ambos casos será necesaria la asistencia del/a Presidente/a o Vicepresidente/a y del/a Secretario/a o persona en quien deleguen.

Este mismo quórum regirá para las sesiones de las Comisiones de Trabajo. 


\section{Artículo 17.- ADOPCIÓN DE ACUERDOS:}

Los acuerdos, tanto del Pleno, como de las Comisiones de Trabajo se adoptarán con carácter general por mayoría simple de los miembros presentes.

En todo caso y no obstante, se requerirá un quorum de dos tercios de los miembros del Pleno cuando se trate de objetivos generales y acuerdos a medio y largo plazo.

\section{CAPITULO IV: DE LA EXTINCIÓN}

\section{Artículo 18.- EXTINCIÓN:}

Se procederá a la extinción del Consejo de la Mujer: miembros.

-Por acuerdo del Pleno, adoptado por mayoría de los dos tercios de los

-Por decisión de la Junta General del Consorcio Guadalteba.

\section{ANEXO 3:}

Tabla 1. Población según edad y sexo

\begin{tabular}{|c|c|c|c|c|c|c|c|c|c|}
\hline & \multicolumn{9}{|c|}{ POBLACIÓN POR EDAD Y SEXO } \\
\hline & \multicolumn{9}{|c|}{ HOMBRES } \\
\hline & $\begin{array}{l}\text { De } 0 \text { a } 4 \\
\text { años }\end{array}$ & $\begin{array}{c}\text { De } 5 \text { a } 9 \\
\text { años }\end{array}$ & $\begin{array}{l}\text { De } 10 \text { a } \\
14 \text { años }\end{array}$ & $\begin{array}{l}\text { De } 15 \\
\text { a } 19 \\
\text { años }\end{array}$ & $\begin{array}{c}\text { De } 20 \text { a } \\
24 \\
\text { años }\end{array}$ & $\begin{array}{l}\text { De } 25 \\
\text { a } 29 \\
\text { años }\end{array}$ & $\begin{array}{c}\text { De } 30 \\
\text { a } 34 \\
\text { años }\end{array}$ & $\begin{array}{c}\text { De } 35 \text { a } \\
39 \\
\text { años }\end{array}$ & \begin{tabular}{|c}
$\mathrm{De}$ \\
$40 \mathrm{a}$ \\
44 \\
años
\end{tabular} \\
\hline ALMARGEN & 40 & 48 & 61 & 54 & 81 & 67 & 87 & 74 & 86 \\
\hline ARDALES & 54 & 58 & 65 & 82 & 80 & 85 & 85 & 100 & 108 \\
\hline CAÑETE LA REAL & 15 & 32 & 25 & 25 & 47 & 64 & 51 & 56 & 78 \\
\hline CAMPILLOS & 228 & 232 & 241 & 258 & 289 & 345 & 334 & 301 & 345 \\
\hline CARRATRACA & 13 & 15 & 21 & 25 & 29 & 22 & 28 & 18 & 32 \\
\hline $\begin{array}{l}\text { CUEVAS DEL } \\
\text { BECERRO }\end{array}$ & 24 & 32 & 24 & 49 & 61 & 54 & 62 & 46 & 57 \\
\hline TEBA & 70 & 78 & 126 & 121 & 138 & 137 & 134 & 124 & 181 \\
\hline SERRATO & & & & & & & & & \\
\hline $\begin{array}{l}\text { SIERRA DE } \\
\text { YEGUAS }\end{array}$ & 95 & 75 & 100 & 87 & 127 & 123 & 141 & 130 & 134 \\
\hline
\end{tabular}

\begin{tabular}{|l|r|r|r|r|r|r|r|r|r|r|}
\hline & $\begin{array}{c}\text { De 45 } \\
\text { a 49 } \\
\text { años }\end{array}$ & $\begin{array}{c}\text { De 50 } \\
\text { a 54 } \\
\text { años }\end{array}$ & $\begin{array}{c}\text { De 55 } \\
\text { a 59 } \\
\text { años }\end{array}$ & $\begin{array}{c}\text { De 60 } \\
\text { a 64 } \\
\text { años }\end{array}$ & $\begin{array}{c}\text { De 65 } \\
\text { a 69 } \\
\text { años }\end{array}$ & $\begin{array}{c}\text { De 70 } \\
\text { a 74 } \\
\text { años }\end{array}$ & $\begin{array}{c}\text { De 75 } \\
\text { a 79 } \\
\text { años }\end{array}$ & $\begin{array}{c}\text { De } 80 \\
\text { a 84 } \\
\text { años }\end{array}$ & $\begin{array}{c}\text { De 85 } \\
\text { y más } \\
\text { años }\end{array}$ & TOTAL \\
\hline ALMARGEN & 94 & 69 & 63 & 41 & 55 & 44 & 33 & 33 & 16 & 1046 \\
\hline ARDALES & 114 & 104 & 82 & 51 & 68 & 41 & 57 & 48 & 22 & 1304 \\
\hline CAÑETE LA REAL & 102 & 106 & 65 & 52 & 56 & 39 & 46 & 32 & 22 & 913 \\
\hline CAMPILLOS & 357 & 338 & 239 & 209 & 203 & 135 & 141 & 95 & 57 & 4347 \\
\hline CARRATRACA & 43 & 40 & 23 & 20 & 18 & 21 & 22 & 18 & 4 & 412 \\
\hline CUEVAS DEL BECERRO & 78 & 59 & 56 & 54 & 56 & 36 & 51 & 31 & 14 & 844 \\
\hline TEBA & 190 & 189 & 130 & 89 & 85 & 68 & 88 & 59 & 17 & 2024 \\
\hline SERRATO & & & & & & & & & & \\
\hline
\end{tabular}




97

\begin{tabular}{|c|c|c|c|c|c|c|c|c|c|c|}
\hline & \multicolumn{10}{|c|}{ POBLACIÓN POR EDAD Y SEXO } \\
\hline & \multicolumn{10}{|c|}{ MUJERES } \\
\hline & $\begin{array}{l}\text { De } 0 \text { a } \\
4 \text { años }\end{array}$ & $\begin{array}{l}\text { De } 5 \text { a } \\
9 \text { años }\end{array}$ & $\begin{array}{c}\text { De } 10 \\
\text { a } 14 \\
\text { años }\end{array}$ & $\begin{array}{l}\text { De } 15 \\
\text { a } 19 \\
\text { años }\end{array}$ & $\begin{array}{c}\text { De } 20 \\
\text { a } 24 \\
\text { años }\end{array}$ & $\begin{array}{l}\text { De } 25 \\
\text { a } 29 \\
\text { años }\end{array}$ & $\begin{array}{c}\text { De } 30 \\
\text { a } 34 \\
\text { años }\end{array}$ & $\begin{array}{l}\text { De } 35 \\
\text { a } 39 \\
\text { años }\end{array}$ & $\begin{array}{c}\text { De } 40 \\
\text { a } 44 \\
\text { años }\end{array}$ & \\
\hline ALMARGEN & 39 & 39 & 49 & 74 & 56 & 77 & 70 & 84 & 70 & \\
\hline ARDALES & 57 & 66 & 63 & 66 & 87 & 90 & 77 & 91 & 106 & \\
\hline CAÑETE LA REAL & 23 & 30 & 23 & 42 & 61 & 55 & 43 & 53 & 60 & \\
\hline CAMPILLOS & 217 & 219 & 232 & 267 & 280 & 278 & 306 & 296 & 312 & \\
\hline CARRATRACA & 7 & 18 & 13 & 22 & 19 & 27 & 26 & 23 & 31 & \\
\hline CUEVAS DEL BECERRO & 22 & 26 & 26 & 46 & 46 & 68 & 42 & 42 & 58 & \\
\hline TEBA & 74 & 95 & 115 & 111 & 127 & 156 & 116 & 131 & 170 & \\
\hline \multicolumn{10}{|l|}{ SERRATO } & \\
\hline SIERRA DE YEGUAS & 77 & 91 & 100 & 80 & 111 & 111 & 130 & 133 & 121 & \\
\hline
\end{tabular}

\begin{tabular}{|l|r|r|r|r|r|r|r|r|r|r|}
\hline & $\begin{array}{c}\text { De 45 } \\
\text { a 49 } \\
\text { años }\end{array}$ & $\begin{array}{c}\text { De 50 } \\
\text { a 54 } \\
\text { años }\end{array}$ & $\begin{array}{c}\text { De 55 } \\
\text { a 59 } \\
\text { años }\end{array}$ & $\begin{array}{c}\text { De 60 } \\
\text { a 64 } \\
\text { años }\end{array}$ & $\begin{array}{c}\text { De 65 } \\
\text { a 69 } \\
\text { años }\end{array}$ & $\begin{array}{c}\text { De 70 } \\
\text { a 74 } \\
\text { años }\end{array}$ & $\begin{array}{c}\text { De 75 } \\
\text { a 79 } \\
\text { años }\end{array}$ & $\begin{array}{c}\text { De 80 } \\
\text { a 84 } \\
\text { años }\end{array}$ & $\begin{array}{c}\text { De 85 } \\
\text { y más } \\
\text { años }\end{array}$ & TOTAL \\
\hline ALMARGEN & 79 & 58 & 47 & 46 & 53 & 41 & 57 & 34 & 26 & 999 \\
\hline ARDALES & 84 & 87 & 63 & 62 & 69 & 61 & 74 & 44 & 37 & 1284 \\
\hline CAÑETE LA REAL & 97 & 84 & 49 & 36 & 46 & 38 & 60 & 54 & 45 & 899 \\
\hline CAMPILLOS & 377 & 329 & 243 & 200 & 189 & 183 & 175 & 133 & 94 & 4330 \\
\hline CARRATRACA & 46 & 25 & 19 & 19 & 20 & 27 & 28 & 22 & 12 & 404 \\
\hline CUEVAS DEL BECERRO & 65 & 63 & 54 & 59 & 50 & 53 & 52 & 51 & 37 & 860 \\
\hline TEBA & 171 & 155 & 98 & 73 & 96 & 96 & 100 & 80 & 56 & 2020 \\
\hline SERRATO & & & & & & & & & & 54 \\
\hline SIERRA DE YEGUAS & 121 & 131 & 110 & 91 & 93 & 54 & 71 & 56 & 54 \\
\hline
\end{tabular}

\begin{tabular}{|c|c|c|c|c|c|c|c|c|c|c|}
\hline & \multicolumn{10}{|c|}{ POBLACIÓN POR EDAD Y SEXO } \\
\hline & \multicolumn{10}{|c|}{ HOMBRES Y MUJERES } \\
\hline & $\begin{array}{l}\text { De } 0 \text { a } \\
4 \text { años }\end{array}$ & $\begin{array}{l}\text { De } 5 \text { a } \\
9 \text { años }\end{array}$ & $\begin{array}{c}\text { De } 10 \\
\text { a } 14 \\
\text { años }\end{array}$ & $\begin{array}{l}\text { De } 15 \\
\text { a } 19 \\
\text { años }\end{array}$ & $\begin{array}{c}\text { De } 20 \\
\text { a } 24 \\
\text { años }\end{array}$ & $\begin{array}{l}\text { De } 25 \\
\text { a } 29 \\
\text { años }\end{array}$ & $\begin{array}{c}\text { De } 30 \\
\text { a } 34 \\
\text { años }\end{array}$ & $\begin{array}{l}\text { De } 35 \\
\text { a } 39 \\
\text { años }\end{array}$ & $\begin{array}{c}\text { De } 40 \\
\text { a } 44 \\
\text { años }\end{array}$ & \\
\hline ALMARGEN & 79 & 87 & 110 & 128 & 137 & 144 & 157 & 158 & 156 & \\
\hline ARDALES & 111 & 124 & 128 & 148 & 167 & 175 & 162 & 191 & 214 & \\
\hline CAÑETE LA REAL & 38 & 62 & 48 & 67 & 108 & 119 & 94 & 109 & 138 & \\
\hline CAMPILLOS & 445 & 451 & 473 & 525 & 569 & 623 & 640 & 597 & 657 & \\
\hline CARRATRACA & 20 & 33 & 34 & 47 & 48 & 49 & 54 & 41 & 63 & \\
\hline CUEVAS DEL BECERRO & 46 & 58 & 50 & 95 & 107 & 122 & 104 & 88 & 115 & \\
\hline TEBA & 144 & 173 & 241 & 232 & 265 & 293 & 250 & 255 & 351 & \\
\hline \multicolumn{11}{|l|}{ SERRATO } \\
\hline \multirow[t]{2}{*}{ SIERRA DE YEGUAS } & 172 & 166 & 200 & 167 & 238 & 234 & 271 & 263 & 255 & \\
\hline & $\begin{array}{l}\text { De } 45 \\
\text { a } 49 \\
\text { años }\end{array}$ & $\begin{array}{l}\text { De } 50 \\
\text { a } 54 \\
\text { años }\end{array}$ & $\begin{array}{l}\text { De } 55 \\
\text { a } 59 \\
\text { años }\end{array}$ & $\begin{array}{c}\text { De } 60 \\
\text { a } 64 \\
\text { años }\end{array}$ & $\begin{array}{c}\text { De } 65 \\
\text { a } 69 \\
\text { años }\end{array}$ & $\begin{array}{c}\text { De } 70 \\
\text { a } 74 \\
\text { años }\end{array}$ & $\begin{array}{l}\text { De } 75 \\
\text { a } 79 \\
\text { años }\end{array}$ & $\begin{array}{c}\text { De } 80 \\
\text { a } 84 \\
\text { años }\end{array}$ & $\begin{array}{l}\text { De } 85 \\
\text { y más } \\
\text { años }\end{array}$ & TOTAL \\
\hline ALMARGEN & 173 & 127 & 110 & 87 & 108 & 85 & 90 & 67 & 42 & 2045 \\
\hline ARDALES & 198 & 191 & 145 & 113 & 137 & 102 & 131 & 92 & 59 & 2588 \\
\hline CAÑETE LA REAL & 199 & 190 & 114 & 88 & 102 & 77 & 106 & 86 & 67 & 1812 \\
\hline CAMPILLOS & 734 & 667 & 482 & 409 & 392 & 318 & 316 & 228 & 151 & 8677 \\
\hline
\end{tabular}




\begin{tabular}{|l|r|r|r|r|r|r|r|r|r|r|} 
CARRATRACA & 89 & 65 & 42 & 39 & 38 & 48 & 50 & 40 & 16 & 816 \\
\hline CUEVAS DEL BECERRO & 143 & 122 & 110 & 113 & 106 & 89 & 103 & 82 & 51 & 1704 \\
\hline TEBA & 361 & 344 & 228 & 162 & 181 & 164 & 188 & 139 & 73 & 4044 \\
\hline SERRATO & & & & & & & & & & \\
\hline SIERRA DE YEGUAS & 246 & 254 & 207 & 183 & 189 & 116 & 137 & 115 & 75 & 3488 \\
\hline
\end{tabular}

\section{ANEXO 4:}

\section{GUIÓN DE ENTREVISTA}

\section{Mujeres pertenecientes a partidos políticos}

EDAD:

PARTIDO POLÍTICO/CARGO:

FORMACIÓN:

1.- ¿Cuánto tiempo llevas en la política?

2.- ¿Qué te llevó a presentarte en las listas de tu partido? ¿Has ostentando alguna concejalía? Cual? En el caso de abandono cuales fueron los motivos?

3.- ¿Cómo te sientes estando dentro de un partido político? Emociones

4.- ¿Cuál es la relación con tus compañeras y compañeros de partido?

5.- ¿Has sentido que tu opinión era tenida en cuenta? ¿Qué facilidades-obstáculos te encuentras?

6.- ¿Hasta qué punto es importante para ti que las mujeres rurales estén en política? ¿Te ves empoderada?

7.- ¿Piensas que las mujeres que viven en pueblos tienen menos oportunidades? ¿En qué sentido?

8.- ¿Qué iniciativas de igualdad concretas ha llevado a cabo tu partido? ¿Está comprometido con la igualdad de género?

9.- ¿Ves necesaria la presión dentro de los partidos para que acaten las medidas de igualdad y de participación política de las mujeres?

10.- ¿Formas parte de alguna asociación de mujeres?

11.- ¿Ves necesaria la existencia de programas para favorecer la igualdad? 
12.- ¿Qué iniciativas de mejora propondrías para mejorar la vida de las mujeres de tu entorno?

13.- Valor que le das al Consejo Comarcal de la Mujer

14.- ¿Te consideras feminista?

\section{GUIÓN DE ENTREVISTA}

\section{Mujeres pertenecientes a Asociaciones}

EDAD:

ASOCIACIÓN/AÑO FUNDACIÓN/CARGO:

FORMACIÓN:

1.- ¿Cuánto tiempo llevas formando parte de la asociación?

2.- ¿Qué te llevó a formar parte de ella?

3.- ¿Cómo te sientes estando dentro? Motivaciones, percepción de empoderamiento. ¿Has sentido que tu opinión era tenida en cuenta? ¿Qué facilidades-obstáculos te encuentras?

4.- ¿Cuál es la relación con tus compañeras y con las mujeres de tu entorno?

5.- Está en vuestros estatutos la promoción de las mujeres y la igualdad de género?, ¿lleváis a cabo iniciativas para cumplir esta premisa?

6.- ¿Qué actividades lleváis a cabo en las asociación? (talleres, campañas, etc.)

7.- ¿Ves necesaria la presión desde las asociaciones para que se acaten las medidas de igualdad y de participación política de las mujeres?

8.- ¿Formas parte de algún mecanismo de decisión político, partido político?

9.- ¿Cuál es la relación con la concejalía de igualdad de tu municipio?

10.- ¿Hasta qué punto es importante para ti que las mujeres rurales estén asociadas?

11.- ¿Piensas que las mujeres que viven en pueblos tienen menos oportunidades? ¿En qué sentido?

12.- Valor que le das al Consejo Comarcal de la Mujer 
13.- ¿Ves necesaria la existencia de programas para favorecer la igualdad? En qué medida han afectado a las mujeres los recortes en igualdad?

14.- ¿Qué iniciativas de mejora propondrías para mejorar la vida de las mujeres de tu entorno?

15.- ¿Te consideras feminista? 
